\title{
UNA REVISIÓN DE LA EXCEPCIONAL POTESTAD DEL PLENO DE LA CÁMARA EX ARTÍCULO 150 DEL REGLAMENTO DEL CONGRESO DE LOS DIPUTADOS.
}

M PILAR GARCÍA ROCHA 


\section{SUMARIO}

1. QUIÉN DEBE DECIDIR LA TRAMITACIÓN EN LECTURA ÚNICA. 1.1. Las facultades de la Mesa y la delimitación de los presupuestos habilitantes. 1.2. Las condiciones formales de la decisión final del Pleno. 2. CUÁNDO ADOPTAR LA DECISIÓN DE TRAMITAR EN LECTURA ÚNICA: UNA PROPUESTA ALTERNATIVA. 3. EL CÓMO ADOPTAR LA DECISIÓN DE TRAMITAR EN LECTURA ÚNICA. 3.1. El valor del precedente parlamentario. 3.2. La dicotomía mayoría simple vs, mayorías reforzadas. 4. CONCLUSIONES. 5 BIBLIOGRAFÍA. 


\title{
UNA REVISIÓN DE LA EXCEPCIONAL POTESTAD DEL PLENO DE LA CÁMARA EX ARTÍCULO 150 DEL REGLAMENTO DEL CONGRESO DE LOS DIPUTADOS.
}

\author{
M PILAR GARCÍA ROCHA \\ Universidad de Murcia ${ }^{1}$
}

\section{QUIÉN DEBE DECIDIR LA TRAMITACIÓN EN LECTURA UNNICA.}

\subsection{Las facultades de la Mesa y la delimitación de los presupuestos habilitantes.}

Los artículos 150.1 del Reglamento del Congreso de los Diputados (RCD) y 129.1 del Reglamento del Senado (RS) establecen, con idéntica literalidad, que cuando concurran los presupuestos habilitantes en ellos descritos en un proyecto o proposición de ley tomada en consideración —en el Congreso de los Diputados-, o en el texto remitido por la Cámara Baja — en el caso del Senado_- será el Pleno de cada una de estas sedes parlamentarias el órgano que adoptará la decisión de tramitar o no esa iniciativa por el procedimiento abreviado de lectura única. Así, pues, los Reglamentos Parlamentarios han otorgado la decisión final de la tramitación de una iniciativa en lectura única al Pleno, pero estableciendo también el papel decisivo de la Mesa, sin cuya propuesta inicial no cabe la intervención del órgano plenario. De este modo, podríamos afirmar que la Mesa de la Cámara propone, previa audiencia no vinculante a la Junta de Portavoces, y el Pleno finalmente dispone. Esta aparentemen-

1 Doctora en Derecho. Profesora Asociada de Derecho Constitucional. Departamento de Fundamentos del Orden Jurídico y Constitucional. Facultad de Derecho. Campus de La Merced. Universidad de Murcia. 30001, Murcia. Email: pilar.garcia.rocha@um.es Este trabajo ha sido realizado en el marco del Proyecto Reforma constitucional: dimensión institucional y territorial (20639/JLI/18) financiado por la Fundación Séneca-Agencia de Ciencia y Tecnología de la Región de Murcia a través de la convocatoria Jóvenes Líderes en Investigación del Subprograma de Apoyo y Liderazgo Científico y la Transición a la Investigación Independiente (Programa Fomento de la Investigación Científica y Técnica 2018).

(C) UNED. Revista de Derecho Politico

N. ${ }^{\circ} 107$, enero-abril 2020, págs 147-179 
te sencilla enunciación alberga, sin embargo, no pocos interrogantes que estamos obligados a resolver ${ }^{2}$.

Por lo que se refiere a ese decisivo papel de la Mesa, debemos empezar por señalar que, si bien estamos ante un órgano de composición política, su función de calificar y dar el trámite correspondiente a las distintas iniciativas parlamentarias no tiene, o no debería tener, naturaleza política. Como señala la mejor doctrina ${ }^{3}$, lo que distingue las funciones de la Mesa de las potestades de la Junta de Portavoces y del Pleno también órganos de composición política, naturalmente- es la sujeción a diferentes parámetros: la Constitución y el Reglamento Parlamentario, en el caso de la Mesa, y el juego de mayorías en el caso de la Junta de Portavoces y del Pleno.

En efecto, el Tribunal Constitucional ha recordado reiteradamente que la Mesa no debe adoptar sus decisiones por criterio de oportunidad política, pues "en tanto que órgano de administración y gobierno interior, [debe] limitar sus facultades de calificación y admisión al exclusivo examen del cumplimiento de los requisitos formales reglamentariamente exigidos, pues, de lo contrario, no sólo estaría asumiendo bajo un pretendido juicio técnico una decisión política que sólo al Pleno corresponde, sino que, además, y desde la óptica de la representación democrática, estaría obstaculizando la posibilidad de que se celebre un debate público entre las distintas fuerzas políticas con representación parlamentaria" ${ }^{4}$, y en ese entendido, lo que efectivamente corresponde a la Mesa "por estar sujeta a la Constitución y a los Reglamentos Parlamentarios que regulan sus atribuciones y funcionamiento, [es] verificar la regularidad jurídica y la viabilidad procesal de la iniciativa, esto es, examinar si la iniciativa cumple con los requisitos formales exigidos por la norma parlamentaria, pero ese examen [...] no puede suponer un juicio de oportunidad política de una iniciativa legislativa"s.

$\mathrm{Y}$ es aquí donde creemos que se encuentra la clave de esta cuestión. Si entendemos que la decisión de optar por el procedimiento legislativo en lectura única es un juicio meramente político que debe adoptar el Pleno, el cometido que a las Mesas de las Cámaras atribuyen expresamente los Reglamentos del Congreso y del Senado quedaría completamente vacío de contenido. Sin embargo, si damos una diferente categorización a las circunstancias habilitantes que recogen tales normas parlamentarias, las atribuciones asignadas a las Mesas cobran todo el sentido que esos preceptos regla-

2 Vid., al respecto, el interesante estudio que realiza sobre esta temática TORRES MURO, I. (1998), en "Los derechos de los parlamentarios", Revista de Derecho Político, 44, 257 y ss., y del mismo autor (1987), en Los órganos de gobierno de las Cámaras. Presidente, Mesa y Junta de Portavoces en el sistema parlamentario español, Madrid, Congreso de los Diputados, 21 y ss.

${ }^{3}$ Vid., al respecto, GARCÍA-ESCUDERO MÁRQUEZ, P. y PENDÁS GARCÍA, B. (1999). "Comentario al artículo 72.2 de la Constitución. Autogobierno de las Cámaras. Sesiones Conjuntas", en ALZAGA VILLAAMIL, O. (Dtor.). Comentarios a la Constitución Española de 1978, Madrid, Edersa, 433 y ss.

${ }^{4}$ Vid., SSTC 40/2003, de 27 de febrero, FJ 7; 78/2006, de 13 de marzo, FJ 3; 158/2014, de 6 de octubre, FJ 4; y 212/2016, de 15 de diciembre, FJ 3 c).

${ }^{5}$ Vid., v.g., SSTC 205/1990, de 13 de diciembre, FJ 6; 38/1999, de 22 de marzo, FJ 3; y más recientemente, 96/2019, de 15 de julio, FJ 6 a). 
mentarios parecen darles: para que el Pleno pueda disponer finalmente, es inexcusable la propuesta previa de la Mesa, que habrá de ajustarse al estricto juicio técnico que el ordenamiento jurídico le encomienda. Juicio que, insistimos, sólo es posible realizar si entendemos por naturaleza que lo aconseje o simplicidad que lo permita de un modo muy distinto al actualmente defendido por la doctrina mayoritaria ${ }^{6}$.

Así, hemos de partir, en primer lugar, del hecho cierto de que la extraordinaria apertura de las normas reglamentarias que establecen tales presupuestos es intencionada por parte del legislador. La definición de los mismos en términos tan poco concretos tiene como objetivo - legítimo - dar al Pleno la máxima libertad posible a la hora de decidir, caso por caso, cuál deba ser el procedimiento a seguir para cada una de las iniciativas legislativas a tramitar.

El conjunto de preceptos que rigen los diferentes procedimientos legislativos tienen en común la búsqueda de la agilidad y flexibilidad de la labor parlamentaria, en justo equilibrio con las debidas garantías a las que se debe someter todo proceso de decisión político-legislativa, de forma que la tarea del Parlamento no encuentre innecesarios obstáculos que la ralenticen y la hagan ineficaz, pero evitando siempre que ese resultado se alcance menoscabando o vulnerando bien los derechos fundamentales de los parlamentarios, o las debidas garantías democráticas que presiden el procedimiento legislativo ${ }^{7}$. De este modo, los Reglamentos Parlamentarios de ambas Cámaras apoderan a sus respectivos Plenos para determinar con un amplísimo margen de discrecionalidad la pertinencia o impertinencia de la tramitación de un proyecto o proposición de ley en lectura única, pero siempre sujetos a los límites propios de los presupuestos habilitantes que en aquéllos se recogen.

En segundo término, también debemos tener presente que, la interpretación que la Cámara debe hacer del alcance de ambos presupuestos debe tener un carácter claramente restrictivo y no expansivo ${ }^{8}$, por cuanto que nos encontramos ante un régimen particular que excepciona el régimen general del procedimiento legislativo ordinario, y que consiste, además, en la disminución de las garantías procedimentales que se establecen en ese otro régimen general.

El mismo criterio debería informar también el juicio de constitucionalidad que el Tribunal Constitucional puede realizar de esa decisión de las Cámaras, pues, en efecto, si bien encuentra el Alto Tribunal muy limitada su capacidad para reconvenir esa decisión del Parlamento garantizada por la autonomía que protege el Texto Fun-

${ }^{6}$ Vid., v.g., GÓMEZ LUGO, Y. (2019). "La tramitación de la reforma constitucional mediante procedimientos legislativos abreviados: un problema de límites procedimentales”, Teoría y Realidad Constitucional, 43, 395 y ss.; GARCÍA-ESCUDERO MÁRQUEZ, P. (2005). "El procedimiento legislativo ordinario en las Cortes Generales: regulación, fases y tipos”, Teoría y Realidad Constitucional, 16, 238 y ss.

Vid., v.g., en este sentido, GARCÍA-ESCUDERO MÁRQUEZ, P. (2007). El procedimiento agravado de reforma de la Constitución de 1978, Madrid, CEPC, 178 y ss.

${ }^{8}$ Vid., v.g., las reflexiones que al respecto realiza GARCÍA MARTíNEZ, M. A. (1987). El procedimiento legislativo, Madrid, Congreso de los Diputados, 299 y ss.; y GARCÍA-ESCUDERO MÁRQUEZ, P. (2005). "El procedimiento legislativo ordinario en las Cortes Generales: regulación, fases y tipos", Teoría y Realidad Constitucional, 16, 211 y ss.

(C) UNED. Revista de Derecho Politico

N. ${ }^{\circ} 107$, enero-abril 2020, págs 147-179 
damental ${ }^{9}$, también está constitucionalmente obligado a intervenir cuando éste incurra en aplicación arbitraria de su propio Reglamento. Y cuando lo haga, debe también atender a la condición excepcional de este procedimiento abreviado y, por tanto, a la interpretación necesariamente restrictiva del alcance de sus presupuestos habilitantes ${ }^{10}$.

La decisión del Pleno sobre si optar o no por el procedimiento legislativo en lectura única no es por tanto libérrima. Cierto es que el Reglamento da una redacción muy abierta a los presupuestos habilitantes, pero no es menos cierto que, como todo concepto jurídico indeterminado, tales supuestos tienen unos perfiles y unos límites - aunque no estén expresamente establecidos en la norma-, y que si el legislador reglamentario hubiera pretendido dotar al Pleno de una potestad absolutamente libre para decidir la tramitación de una iniciativa legislativa por esta vía podría haberlo hecho y no lo hizo ${ }^{11}$.

Estamos, por otra parte, ante dos supuestos habilitantes perfectamente diferenciables de condición alternativa y no complementaria. Basta que uno de ellos concurra para que la Cámara pueda optar por el trámite legislativo en lectura única. Razón por la cual, la delimitación del ámbito objetivo de cada uno de ellos debe ser diferente y estar separada, sin que existan elementos comunes en su configuración. Lo cual no es incompatible con que, en determinadas circunstancias, puedan concurrir respecto de una misma iniciativa las condiciones objetivas tanto de un presupuesto como del otro ${ }^{12}$.

Ninguna de las dos circunstancias habilitantes es identificable, ni plena ni parcialmente, con la urgencia en la tramitación de una iniciativa. Las razones de urgencia, por extraordinarias que éstas puedan ser, no son causa para proceder a la apertura del procedimiento en lectura única. La urgencia abre un procedimiento abreviado diferente que, además, es compatible con el procedimiento en lectura única, lo que refuerza ese argumento inicial. El hecho de que la tramitación en lectura única conlleve el acortamiento de la duración del procedimiento legislativo por cuanto supone la omisión de la fase de Comisión, en una Cámara y/o en la otra, no es más que una consecuencia colateral de la aplicación — concurrente o no con el trámite de urgencia- de un tipo de procedimiento motivado por otras causas y que persigue otros fines.

La naturaleza de la iniciativa legislativa que aconseja la tramitación en lectura única no es, ni mucho menos, la eventual relevancia política, social, económica o jurídica de la norma a tramitar. Tampoco se alude con ello a determinados contenidos

9 Vid., v.g., al respecto, ARAUJO DÍAZ DE TERÁN, M. (2012). "Comentario al artículo 150”, en RIPOLLÉS SERRANO, M. R. (Coord.). Comentarios al Reglamento del Congreso de los Diputados, Madrid, Congreso de los Diputados, 1064 y ss.

${ }_{10}$ Vid., v.g., SANTAOLALLA LÓPEZ, F. (2013). Derecho Parlamentario Español, Madrid, Dyckinson, 22 y ss.

${ }_{11}$ Vid., v.g., BIGLINO CAMPOS, P. (2011). Voz "Procedimiento Legislativo", en ARAGÓN REYES, M. (Dtor.), Temas Básicos de Derecho Constitucional, Tomo II, Organización General y Territorial del Estado, Navarra, Civitas, 158 y ss.; y GARCÍA-ESCUDERO MÁRQUEZ, P. (2006). El procedimiento legislativo ordinario en las Cortes Generales, Madrid, CEPC, 23 y ss.

${ }^{12}$ Vid., v.g., SANTAOLALLA LÓPEZ, F. (2013). Derecho Parlamentario..., opus cit., 240 y ss. 
materiales susceptibles de lectura única. No hay ni reservas materiales a favor de la lectura única, ni materias vetadas a la misma. Esta variante procedimental tiene, por tanto, carácter plenamente transversal. Se puede proyectar, en principio, sobre cualquier tipo de iniciativa, ya tenga condición de ley ordinaria, orgánica o incluso estemos ante una reforma del Texto Constitucional ${ }^{13}$. Entendemos que las únicas leyes que poseen una naturaleza distinta a las demás que aconsejan o, incluso, exigen su tramitación en lectura única sin paso por Comisión, son aquellas a las que nuestro ordenamiento jurídico reconoce excepcionalmente la condición de norma pactada o paccionada. Tal sería el caso de la Ley Orgánica de Reintegración y Amejoramiento del Régimen Foral de Navarra (LORAFNA), respecto de la cual la Resolución de la Presidencia del Congreso de los Diputados, de 16 de marzo de 1993, sobre procedimiento a seguir para la tramitación de la reforma de los Estatutos de Autonomía, establece como inexcusable su tramitación en lectura única (apartado $4^{\circ}$ ), precisamente por la especial y distinta naturaleza de este tipo normativo.

Aunque no estén incluidas en ese precepto que exige tramitación en lectura única, entendemos que el Pleno podrá abrir este procedimiento abreviado para aquellos proyectos y proposiciones de ley de idéntica condición, esto es, las leyes estatales que recogen el Concierto Económico del País Vasco, el Convenio Económico de Navarra, y las que determinan el cálculo de los cupos correspondientes; así como las que incorporan a nuestro ordenamiento jurídico los acuerdos de cooperación celebrados entre el Estado y las diferentes confesiones religiosas. También entendemos que podrían tramitarse en lectura única, en aplicación de este primer presupuesto habilitante, aquellas decisiones legislativas del Parlamento que requieren una ratificación a través de un debate y votación de conjunto, sin modificaciones al texto. Tales serían los casos de las autorizaciones de Tratados Internacionales ${ }^{14}$, y de la intervención aprobatoria de las Cortes respecto de aquellas reformas de Estatutos de Autonomía de las Comunidades Autónomas creadas por la vía extraordinaria del artículo 151 CE y la disposición transitoria $2^{\mathrm{a}} \mathrm{CE}$ que se limiten a la modificación del régimen de autogobierno de la Comunidad y no afecten a las relaciones de ésta con el Estado.

Por el contrario, según nuestro criterio, el hecho de que cualquier otro tipo de iniciativa legislativa distinta de las enunciadas pudiera llegar al Parlamento con un contenido muy consensuado por las fuerzas políticas mayoritarias en la Cámara y que, por tanto, resulte previsible que no va a sufrir modificaciones importantes durante el

${ }_{13}$ Tanto en la STC 27/2000, de 31 de enero FJ 3, como las obras de GARCÍA ROCA, J. (2014). Pautas para una reforma constitucional, Madrid, Aranzadi, 56 y ss.; GARCÍA-ESCUDERO MÁRQUEZ, P. (2009). "La reforma del artículo 135: ¿son suficientes trece días para la tramitación parlamentaria de una reforma constitucional”, Cuadernos de Derecho Público, 38, 79 y ss.; y ALZAGA VILLAAMIL, O. (1976). "Contribución al estudio del derecho parlamentario", Revista de derecho público, 62, 23 y ss., se pone de manifiesto este extremo.

${ }^{14}$ SANTAOLALla LÓPEZ, F. (1981). "La ley y la autorización de las Cortes a los Tratados Internacionales”, Revista de Derecho Político, 1, 29 y ss.; y del mismo autor, (2006). "Decreto ley, ley y tratado internacional. Comentario a la STC 155/2005, de 9 de junio”, Teoría y Realidad Constitucional, 18, 400 y ss.

(C) UNED. Revista de Derecho Politico

N. ${ }^{\circ} 107$, enero-abril 2020, págs 147-179 
procedimiento legislativo correspondiente, no cambia la naturaleza de dicho proyecto o proposición de ley, no la convierte en norma pactada al amparo de ninguna disposición constitucional o legislativa de nuestro ordenamiento jurídico. Estos acuerdos políticos extraparlamentarios no son, por supuesto, título suficiente para sustituir la labor constitucional de las Cámaras, que debe garantizar siempre la no vulneración de los derechos de participación política de las minorías parlamentarias ${ }^{15}$. Es por ello que, salvo que tales iniciativas se pudieran acoger al segundo de los presupuestos habilitantes porque su formulación resultara suficientemente sencilla como para ser discutidas directamente en el Pleno, no procedería en estos casos, por infracción de los propios límites reglamentarios de la figura, la apertura de procedimiento legislativo en lectura única.

Por lo que hace a ese segundo presupuesto habilitante, no podemos identificar simplicidad de formulación de la iniciativa legislativa con brevedad del texto o con que éste resulte razonable, comprensible e inteligible, como viene haciendo — con mayor o menor claridad - la jurisprudencia del Tribunal Constitucional. Una iniciativa legislativa puede ser, para ese observador razonable al que se ha referido el Tribunal ${ }^{16}$, breve en su extensión, que su redacción sea suficientemente comprensible e inteligible y que, además, su contenido sea razonable a ojos de cualquier observador, pero ello no siempre garantizará que dicho texto tenga unas condiciones de formulación con ausencia de complejidad que permita al Pleno prescindir de la labor preparatoria de la Comisión competente.

Entendemos que, en estos supuestos, la clave para deslindar el alcance de ese concepto jurídico indeterminado es poner en conexión las condiciones del texto presentado con la finalidad y las consecuencias procedimentales que el trámite en lectura única comporta. Esto es, el parámetro para medir hasta qué punto un texto es suficientemente sencillo como para abrir este procedimiento abreviado es cómo de imprescindible sea, en términos de garantías constitucionales, su paso por Comisión, es decir, hasta qué punto su tramitación directa por el Pleno podría cumplir suficientemente con las garantías mínimas que integran el contenido del ius in officium de los parlamentarios ${ }^{17}$.

Nos encontramos, por tanto, ante una disyuntiva que habrá que resolver caso por caso, resultando imposible establecer reglas generales completas que nos puedan

15 Vid., en sentido contrario, GÓMEZ LUGO, Y. (2019): “ El primero de los supuestos, esto es, cuando la naturaleza de un proyecto o de una proposición lo aconseje, parece referirse a textos lo suficientemente consensuados por las fuerzas políticas que hacen innecesaria la discusión y votación que tienen lugar en sede de Comisión, por lo que la tramitación se acelera suprimiendo esta fase en "La tramitación de la reforma constitucional mediante procedimientos legislativos abreviados: un problema de límites procedimentales", opus cit., 397.

${ }^{16}$ Vid., STC 238/2012, de 13 de diciembre, FJ 4; ATC 141/2016, de 19 de julio, FJ 6; STC 129/2913, de 4 de junio, FJ 9; y STC 185/2016, de 3 de noviembre, FJ 7 c).

17 Vid., una pequeña síntesis de la doctrina del Tribunal Constitucional sobre el contenido del ius in officium de los parlamentarios a los efectos que aquí interesan en STC 96/2019, de 15 de julio, FJ 3. 
$\operatorname{guiar}^{18}$. Aun así, entendemos que se pueden establecer algunos parámetros de exclusión. Esto es, según nuestro criterio, habría que presumir que algunas iniciativas legislativas tendrán siempre un nivel de complejidad tal que no proceda el trámite en lectura única. Tal sería el caso de las leyes de Presupuestos Generales del Estado, las de Estabilidad Presupuestaria y otras referidas a distintos regímenes fiscales, siempre y cuando, claro está, se trate de la tramitación de normas completas con estos contenidos, ya que ningún obstáculo habría en optar por el trámite de lectura única para la elaboración de puntualísimas y sencillas modificaciones de este tipo de leyes ${ }^{19}$. Razón por la cual, ni siquiera respecto de ellas podríamos hablar de una exclusión absoluta ratione materiae ${ }^{20}$.

Nuestro argumento de que, así entendidos los presupuestos habilitantes previstos por el Reglamento, la Mesa puede y debe valorar su concurrencia, encuentra refuerzo en la propia doctrina del Tribunal Constitucional, que también ha establecido reiteradamente que la verificación del cumplimiento de las correspondientes formalidades por parte de las Mesas puede extenderse a "una verificación liminar de la conformidad a Derecho de la pretensión deducida, junto a un juicio de calificación sobre la idoneidad o procedencia del procedimiento parlamentario elegido" ${ }^{21}$.

${ }_{18}$ Son muy interesantes las reflexiones que al respecto hace MARTÍNEZ SOSPEDRA, M. (2010) en "La costumbre como fuente de Derecho Parlamentario. Precedentes, usos y prácticas parlamentarias en la doctrina del Tribunal Constitucional", Corts. Anuario de Derecho Parlamentario, 23, 275 y ss.; y GARCÍA-ESCUDERO MÁRQUEZ, P., Manual de técnica legislativa, Madrid, Civitas, 2011, 10 y ss.

19 No desconocemos que el art. 134 RCD se refiere expresamente a la intervención de la Comisión cuando regula el procedimiento legislativo de la Ley de Presupuestos Generales del Estado. Ocurre sin embargo que tal y como ha establecido muy claramente el Tribunal Constitucional en reiteradas sentencias y ha acogido la doctrina más autorizada (vid., por todas, la STC 27/2000, de 31 de enero, FJ 3; y, también, por todos, GARCÍA-ESCUDERO MÁRQUEZ, P. (2009). "La reforma constitucional del artículo 135...”, opus cit., 79 y ss.), el procedimiento legislativo en lectura única tiene un marcado carácter transversal, pudiendo proyectarse respecto de cualquier tipo de materia, incluso sobre aquéllas que requieren un procedimiento especial específico (incluidas las leyes orgánicas o las reformas de la Constitución). Y ello, además, con independencia de que la regulación reglamentaria de esos procedimientos especiales recoja la fase de Comisión, como sucede con la previsión del artículo 154 RS, relativo a la reforma constitucional. Al margen de las especialidades de su procedimiento propio, las Leyes de Presupuestos no tendrían nunca la naturaleza exigida por tales preceptos para su tramitación en lectura única, ni la simplicidad a la que se alude como segunda causa habilitante, salvo en el caso de mínimas intervenciones de modificación de la ley completa ya vigente, que podría eventualmente cumplir con este segundo presupuesto.

20 REDONDO GARCÍA, A. M. (2001). "El derecho de enmienda como instrumento de integración del pluralismo político en la fase central de los procedimientos legislativos de las Cortes Generales", Revista de Derecho Político, 50, 189 y ss.; MERINO MERCHÁN J. F. y DE LA PEÑA RODRÍGUEZ, L. (1991). "Las facultades de calificación de las enmiendas por las Mesas de las Cámaras", Revista de las Cortes Generales, 23, 133 y ss.; ARCE JANÁRIZ, A. (1994). "El derecho de enmienda visto por el Tribunal Constitucional”, Revista Española de Derecho Constitucional, 41, 151 y ss.; y DICKMANN, R. (1995). "L'esercizio dell'iniziativa legislativa”, Rivista trimestrale di Diritto pubblico, 1, 5 y ss.; y DE LA PEÑA RODRÍGUEZ, L. (1998). Calificación y admisión a trámite de iniciativas legislativas, Madrid, V Jornadas de Derecho Parlamentario, 351 y ss.

21 Entre otras, SSTC 205/1990, de 13 de diciembre, FJ 6; 225/1992, de 14 de diciembre, FJ 4; ATC 155/1993, de 24 de mayo, FJ 3; y STC 41/1995, de 13 de febrero, FJ 2.

(C) UNED. Revista de Derecho Politico

N. ${ }^{\circ}$ 107, enero-abril 2020, págs 147-179 
A nuestro parecer, éste sería uno de los casos en los que tal interpretación extensiva de la potestad de las Mesas encuentra todo el sentido. Es por ello que no compartimos la postura de la doctrina ${ }^{22}$ cuando se afirma, en congruencia con el modo de entender la configuración de los presupuestos habilitantes de la lectura única que censuramos que "el acuerdo de la Mesa irá precedido de una valoración sobre la existencia de consenso suficiente entre las fuerzas políticas con representación parlamentaria, que justifique esta agilización procedimental", en la idea de que "el factor clave para la fijación del supuesto de hecho del procedimiento de lectura única lo constituye la existencia de consenso político suficiente para lograr el beneplácito de la Cámara ${ }^{23}$ ", por lo que "este elemento deberá ser tenido en cuenta por la Mesa de la Cámara con carácter previo a su propuesta de tramitación" ${ }^{24}$. Lo que convertiría a la Mesa en un mero órgano de verificación de la presumible existencia de un consenso político mayoritario sobre el tipo de tramitación — desvinculado de la naturaleza de la iniciativa y de la simplicidad de su formulación - que, a nuestro juicio, no se compadece bien con las atribuciones que a las Mesas les reconocen los respectivos Reglamentos Parlamentarios, en general, y los concretos preceptos 150.1 RCD y 129.1 RS, en particular.

Así, en contra del criterio doctrinal dominante ${ }^{25}$, entendemos que la Mesa está habilitada para elaborar un juicio formal sobre la concurrencia de alguno de los dos presupuestos habilitantes de la lectura única, tal y como aquí se han categorizado. Y podría, por tanto, no proponer al Pleno la decisión de tramitar en lectura única la iniciativa pese a que la Junta de Portavoces le comunicara la existencia de consenso mayoritario previo de los Grupos Parlamentarios. Esto es, entendemos que no es un acto debido de la Mesa proponer al Pleno la tramitación en lectura única en el caso de que resulte esperable, tras oír a la Junta de Portavoces, que el Pleno votaría mayoritariamente a favor de implementar este procedimiento legislativo abreviado.

Lamentablemente, no existe documento público en el que haya quedado registrada la motivación que en cada caso hayan podido utilizar las Mesas de las Cámaras para justificar la decisión de proponer o no al Pleno la tramitación de un determinado proyecto o proposición de ley en lectura única. Pese a que es reiterada la jurisprudencia constitucional que da cuenta de la relevancia de que las Mesas motiven sus decisiones $^{26}$, concretamente, en relación a esta decisión el Tribunal Constitucional rebaja notablemente esa exigencia en el entendido de que "no se deduce de las normas

${ }^{22}$ En este mismo sentido se ha manifestado recientemente RIDAO MARTIN, J. (2018), en "La tramitación directa de las leyes: el procedimiento de lectura única a revisión”, Revista General de Derecho Constitucional, 28, 14.

23 La cursiva es mía.

${ }^{24}$ GÓMEZ LUGO, Y. (2008). Los procedimientos legislativos especiales en las Cortes Generales, Madrid, Congreso de los Diputados, 331.

25 Vid., por todos, GÓMEZ LUGO, Y. (2008). Los procedimientos legislativos..., opus cit., 325-326.

26 Vid., por todas, STC 78/2006, de 13 de marzo, FJ 3 a). 
parlamentarias que la Mesa haya de motivar la propuesta de que una determinada iniciativa se tramite mediante el procedimiento legislativo de lectura única" ${ }^{27}$.

$\mathrm{Y}$, efectivamente, es manifiesta la ausencia de fundamentación exigida por el ordenamiento jurídico acerca de las razones que impulsan a los órganos legitimados, ex Reglamento, para proponer y aceptar dicho cauce especial de tramitación. Los cuerpos normativos encargados de estructurar el procedimiento legislativo no exigen a la Junta de Portavoces, en ningún momento, que deje constancia fehaciente de las razones que expuso a la Mesa de la Cámara en el desarrollo del trámite de audiencia —que le fue concedido reglamentariamente - para proponer la oportunidad de esta tramitación especial. Tampoco se requiere al órgano de gobierno parlamentario que especifique las consideraciones que, después de escuchar las alegaciones efectuadas por la Junta de Portavoces donde se exponía la causa que, a su juicio, existía para impulsar la tramitación en lectura única, le conducían a presentar al órgano plenario dicha propuesta de trámite. Y en la continuidad de las ausencias testimoniales descritas observamos que, tampoco está contemplado mandato alguno que exija al Pleno una justificación por escrito que sustente la posición adoptada con respecto a la oportunidad de tramitación, ni tan siquiera es conminado este órgano a explicar en sede asamblearia de forma oral las razones que motivaron el sentido de la votación efectuada.

La existencia y el correspondiente registro de los documentos enunciados podrían dar testimonio objetivo de la necesidad de abandonar la tramitación legislativa ordinaria. Por el contrario, su ausencia impide dar cumplimiento efectivo al principio de publicidad inherente a la actividad de las Cortes como órgano máximo de representación popular, al tiempo que niega al operador jurídico la posibilidad de estudiar y analizar si aquellos presupuestos que impulsaron a los órganos parlamentarios citados a abandonar el cauce ordinario de tramitación, les habilitaban realmente para tomar una decisión tan importante como la que nos ocupa.

Así las cosas, una vez realizada la propuesta favorable por parte de la Mesa para tramitar la iniciativa legislativa en lectura única, corresponde al Pleno ratificar o no esa decisión — ahora sí, en virtud de un criterio de oportunidad política- Nada impediría, pues, que pese a que pudiera concurrir alguno de los presupuestos habilitantes que abren la puerta a la tramitación en lectura única - y así lo hubiera establecido la Mesa de la Cámara - el Pleno pudiera decidir que se continuara con la tramitación legislativa ordinaria al completo.

Hasta la fecha, esta controversia de orden técnico carecía de especial trascendencia práctica pues la equivalencia de las mayorías representadas en las Mesas de las Cámaras y en los Plenos hacía que éstas no se negaran nunca a proponer la tramitación de una iniciativa en lectura única si, una vez oída la Junta de Portavoces, constataban que existía acuerdo mayoritario de los Grupos Parlamentarios a tal efecto. Sin embargo, tras la moción de censura aprobada el 1 de junio de 2018, por la que se invistió Presidente del Gobierno al líder del Partido Socialista, tales equilibrios se rompieron,

${ }^{27}$ Vid., ATC 9/2012, de 13 de enero, FJ 3.

(C) UNED. Revista de Derecho Político

N. ${ }^{\circ} 107$, enero-abril 2020, págs 147-179 
careciendo ahora los Grupos Parlamentarios que apoyaron al Gobierno en el Congreso de los Diputados de mayoría en la Mesa de la Cámara Baja.

Y en efecto, ha sucedido lo que hasta ahora había sido inédito: que la Mesa del Congreso rechazara la tramitación solicitada por los proponentes de una iniciativa legislativa que cuentan con mayoría suficiente en el Pleno. Esta situación ha tenido lugar con la Proposición de Ley Orgánica de reforma de la Ley Orgánica 2/2012, de 27 de abril, de Estabilidad Presupuestaria y Sostenibilidad Financiera. Tras la toma en consideración de la iniciativa y tras retrasar hasta en dos ocasiones la decisión ${ }^{28}$, la Mesa del Congreso de los Diputados decidió dar trámite de procedimiento legislativo ordinario a la propuesta — sin que conste en el Diario de Sesiones ni en el Boletín Oficial de las Cortes Generales la correspondiente motivación-.

La polémica política en torno a esta decisión que condicionó decisivamente la tramitación de la norma fue de notable magnitud y culminó con la interposición de recurso de amparo el 27 de diciembre de 2018, por parte del Grupo Parlamentario Socialista contra el citado acuerdo de la Mesa, por presunta vulneración del artículo 23 CE en conexión con el artículo 150 del Reglamento del Congreso de los Diputados y que ha sido desestimado por STC 110/2019, de 2 octubre. Este pronunciamiento publicado con posterioridad al primer envío de este trabajo a la Revista en la que ahora ve la luz, el Tribunal Constitucional ha acogido la tesis aquí defendida. Ha establecido, en la primera oportunidad que ha tenido de hacerlo, que la Mesa debe enjuiciar la concurrencia o no de los presupuestos habilitantes que abren la puerta a la lectura única y, en consecuencia, proponer o no al Pleno tal tramitación, si procede. $\mathrm{Y}$ al contrario, puede no proponerla si entiende que ni la naturaleza de la iniciativa lo aconseja, ni la simplicidad de su formulación permite acudir a este trámite abreviado. Decisión de no proponer que puede adoptar incluso antes de dar audiencia a la Junta de Portavoces y, por supuesto, al margen del mayor o menor consenso político que al respecto pudiera darse en el Pleno ${ }^{29}$.

${ }^{28}$ Vid., todo el iter de la tramitación en:

http://www.congreso.es/portal/page/portal/Congreso/Congreso/Iniciativas?_pir ef73_2148295_73_1335437_1335437.next_page=/wc/servidorCGI\&CMD =VERLST \&BASE =IW12\&PIECE = IW A2\&FMT = INITXD1S.fmt\&FORM1 = INITXLUS.fmt\&QUERY =\%28I\%29. ACIN1.+\%26+\%28LEY+ESTABILIDAD+PRESUPUESTARIA\%29.ALL.\&DOCS=1-1. Página consultada el 16 de diciembre de 2019, a las 19.00 horas.

${ }^{29}$ STC 110/2019, de 2 de octubre, FJ 3 A b): "No mejor suerte ha de correr, de otra parte, la segunda de las argumentaciones que la demanda expone para censurar que la mesa no diera curso hacia el pleno, sin mayor comprobación o examen, a la petición de tramitación especial que se dedujo. Los demandantes evocan al respecto la constante doctrina del Tribunal conforme a la cual las funciones de las mesas de las cámaras en punto a la calificación y admisión a trámite de los escritos y documentos de naturaleza parlamentaria son, con alguna muy limitada salvedad que no hace al caso mencionar, y sin perjuicio de que otra cosa se disponga en los reglamentos respectivos, de estricta verificación formal, a fin de apreciar exclusivamente la regularidad jurídica y viabilidad procesal de unas iniciativas u otras y sin que a las mesas les corresponda emplear o expresar, a estos efectos, un juicio de oportunidad en los casos en que tal apreciación esté atribuida al pleno de la cámara [por todas las múltiples resoluciones en este sentido, SSTC 44/2010, de 27 de julio, FJ 5; 109/2016, FJ 4 a); 212/2016, de 15 de diciembre, FJ 


\subsection{Las condiciones formales de la decisión final del Pleno.}

El hecho de que sea el Pleno el órgano encargado de adoptar en último término la decisión de tramitar la iniciativa en cuestión en lectura única, pone de manifiesto la protección que el principio de disponibilidad dispensa a las Cámaras con respecto a los trámites del procedimiento legislativo, a su cronología y a la libertad de ordenación procedimental. Este principio incluye la competencia no solo para que el Pleno decida el procedimiento aplicable, sino también para resolver las cuestiones incidentales que en él pudieran producirse ${ }^{30}$. En este orden de cosas, y una vez que el Pleno ha manifestado su voluntad sobre la iniciativa en curso, ésta debe ser dada a conocer por los cauces que oportunamente, para este cometido, ha establecido el legislador. Y en la necesidad de dejar constancia de aquella voluntad emitida, y en el propósito de reconocer, de manera plenamente efectiva, el principio de publicidad inherente al acto jurídico que nos ocupa, se dará siempre de ello testimonio por escrito.

5; 224/2016, de 19 de diciembre, FJ 4, y 34/2018, FJ 4 b)]. Esta jurisprudencia no es de aplicación a lo que aquí se plantea. Ante todo, y en atención a lo dispuesto en el reglamento, porque el acuerdo adoptado por la mesa en orden a no proponer al pleno el recurso al procedimiento de lectura única no fue tanto, en rigor, una resolución sobre la calificación y admisión a trámite de iniciativa alguna (art. 31.1.4 RCD), cuanto más bien, o sobre todo, acerca de la «tramitación» de una iniciativa ya calificada y admitida (la proposición de ley orgánica presentada, junto a otros grupos, por el socialista), decisión, esta segunda, que le corresponde siempre a la mesa «de acuerdo con las normas establecidas en este reglamento» (art. 31.1.5 RCD); esto es, con arreglo a lo dispuesto en el repetido artículo 150.1 RCD y a la facultad de propuesta que en él se confiere, exclusivamente, al órgano de gobierno de la cámara, facultad que desaparecería, sin más, si se estuviera a lo que la demanda arguye. En segundo lugar, no es dable aceptar la opinión de los demandantes según la cual la mesa no podría ponderar, para proponer la tramitación controvertida, o para no hacerlo, criterios de oportunidad relativos, ante todo, a la concurrencia o no, en cada caso, de los supuestos que pueden justificar, mediante enunciados inevitablemente abiertos, el acudir a este procedimiento legislativo especial (la «naturaleza» o la «simplicidad de formulación» del texto del proyecto o proposición), apreciaciones de oportunidad que no pueden confundirse con valoraciones meramente ideológicas o partidistas y que este Tribunal ha reconocido que la propia mesa realiza, y así es inexcusable, al formular esta específica propuesta o al decidir no hacerla [SSTC 185/2016, de 3 de noviembre, y 215/2016, ya citada, FJ 5 c) de una y otra, que se refieren expresamente al «criterio de oportunidad de la mesa del Congreso de los Diputados al proponer la tramitación de la proposición de ley por el procedimiento en lectura única»]. Debe advertirse por último, en estrecha relación con lo expuesto, que el órgano de gobierno de la cámara cuya función es, en general, técnico-jurídica, para ordenar y racionalizar el funcionamiento de la respectiva asamblea [STC, entre otras, 109/2016, FJ 6 C)], no puede abdicar de esta potestad de examen y objetiva ponderación de circunstancias cuando considere la oportunidad de formular su propuesta al pleno, ya sea de oficio, ya sea, como en este supuesto, porque así se le solicite. El Reglamento del Congreso, al establecer la iniciativa a estos efectos de la mesa, ha introducido un trámite que está al servicio objetivo de la debida protección de las minorías ante un procedimiento legislativo especial, y de extrema concentración, en el que las posibilidades ordinarias para la deliberación, transacción e integración de voluntades entre diputados y grupos (para alcanzar, en suma, compromisos políticos) quedan, por decisión última de la mayoría, y como se dijo, notablemente reducidas [fundamento jurídico 2 B c) que antecede]. No se trata, ciertamente, de una exigencia parlamentaria que derive directamente de la Constitución o que esta imponga, pero, una vez establecida por el reglamento, ha de ser cumplida y respetada".

30 STC 136/2011, de 13 de septiembre de 2011, FFJJ 7 y 8.

(C) UNED. Revista de Derecho Político

N. ${ }^{\circ} 107$, enero-abril 2020, págs 147-179 
Sabido es que el Pleno, como órgano colegiado, está integrado por una pluralidad de personas encargadas de actualizar la función que, constitucional y reglamentariamente, le ha sido encomendada ${ }^{31}$. Función de la que se ocupan los Diputados y Senadores dentro de cada uno de las sedes plenarias legítimamente constituidos en las Cámaras Baja y Alta, respectivamente, y que tiene lugar al concurrir, de forma conjunta, las voluntades de los sujetos que lo integran. Es, por tanto, la confluencia de dichas voluntades lo que da lugar a la formación y manifestación de una única voluntad final, que es la voluntad del órgano que estudiamos.

Pero a pesar de que la regulación de la actividad parlamentaria goza del abrigo del principio de disponibilidad, en el proceso de construcción volitiva que estudiamos se plantea la necesidad de articular las necesarias estructuras que coordinen el trabajo y las manifestaciones individuales de sus miembros, ya que dichas voluntades, por sí solas, carecen de eficacia jurídica en este escenario. Es indispensable, por tanto, que la concatenación de los actos jurídicos realizados por los sujetos tenga el adecuado desarrollo para que la formación de la voluntad se constituya como actividad imputable al órgano ${ }^{32}$.

La regulación de las normas que estructuran los mecanismos que venimos anunciando para la adecuada articulación del proceso de toma de decisiones, también va a actuar como garantía de las relaciones entre el Estado y la comunidad política. Y en virtud de esta consideración, únicamente puede acometerse esta actividad nuclear a través de los procedimientos que, de forma adecuada, permitan la formación inequívoca de la voluntad plenaria. Se salvaguarda así, como decíamos, la relación protegida por nuestro Texto Constitucional entre el órgano de representación popular y el ciudadano ${ }^{33}$.

Como es conocido, el debate y la deliberación que se producen en el Pleno estructuran la columna vertebral del procedimiento legislativo. Y para que el mismo tenga validez, se le exige el cumplimiento de una secuencia de condiciones derivadas, a su vez, de su naturaleza de órgano colegiado. En este orden de cosas, es necesario ensamblar una cadena de mecanismos concretos tendentes a coordinar las voluntades individuales de sus miembros para poder construir una voluntad única del órgano que posea relevancia jurídica ${ }^{34}$.

Elementos determinantes para la adecuada configuración de este objetivo serán, pues, la necesidad de fijar sus reuniones, el establecimiento de los agentes llamados a participar en las mismas, la articulación del modo y manera tanto de la intervención

31 GARRIDO FALLA, F. (2012). Tratado de Derecho Administrativo, Madrid, Tecnos, 127.

32 GALEOTTI, S. (1975). Contributo alla Teoria del procedimento legislativo, Urbino, Facoltà di Giurisprudenza, Universidad degli Studi di Urbino, Giuffrè, 278 y ss.

33 GARCÍA DE ENTERRÍA, E. y FERNÁNDEZ RODRÍGUEZ, T.R. (1985). Curso de Derecho Administrativo, Madrid, Civitas, 87 y ss.; y CASSAGNE, J. C. (1998). Derecho Administrativo, Buenos Aires, Abeledo Perrot, 99.

34 GARCÍA-TREVIJANO FOS, J. A. (1964). “Tratado de Derecho Administrativo”, Revista de Derecho Privado, Madrid, 379 y ss. 
de sus miembros como de la postura adoptada sobre la iniciativa legislativa que se debate, que en este caso, supone la configuración definitiva de la voluntad parlamentaria.

La convocatoria del órgano plenario en cada una de las Cámaras corresponde a sus Presidentes. En ocasiones, esta decisión es tomada de manera individual y en otras se materializa consensuando el criterio del Presidente con el de los demás miembros de la Mesa de la Cámara correspondiente, o tras la consulta con la Junta de Portavoces. También la fijación del orden del día y sus modificaciones son considerados elementos sustanciales del debate y cobran una importancia capital ya que, solo se podrán discutir en el órgano plenario las materias incluidas en él. Las modificaciones del orden del día solo serán aceptadas si se adoptan en cumplimiento de los requisitos exigidos, tendentes, como no podía ser de otro modo, a evitar las posibles vulneraciones que dichas variaciones pudieran provocar en el debate.

Para que sea posible proceder a la votación en la que el Pleno acuerde la tramitación por lectura única de una determinada iniciativa, el asunto objeto de trámite debe estar incluido como un punto en el orden del día ${ }^{35}$. La excepción a esta regla general queda contemplada en el art. 67.4 RCD cuando establece que, la Junta de Portavoces podrá acordar, por razones de urgencia y unanimidad, y a iniciativa de un Grupo Parlamentario o del Gobierno, la inclusión en el orden del día de un determinado asunto, aunque éste no hubiere cumplido todavía los trámites reglamentarios.

En ocasiones, se ha denunciado como vicio procesal el que una sesión plenaria de carácter extraordinario sea convocada con el fin de decidir sobre la tramitación en lectura única de una concreta iniciativa. La tesis argumental de la denuncia se sustentaba en lo establecido en el precepto anteriormente citado donde se estipula que, únicamente, la Junta de Portavoces y por unanimidad, puede modificar el orden del día del Pleno. El vicio procesal que se alegaba era el hecho de que no hubiera concurrido la unanimidad exigida para introducir en el orden del día del Pleno la cuestión relativa a la tramitación del proyecto de ley por el procedimiento de lectura única ${ }^{36}$.

Pero también encontramos argumentos que intentan rebatir esta postura sosteniendo que las sesiones extraordinarias son aquéllas que tienen lugar fuera del periodo ordinario de sesiones definido en el artículo 73.1 CE, por lo que de celebrarse un Pleno para debatir la oportunidad de tramitar una iniciativa en lectura única, habría sido una sesión plenaria de carácter ordinario convocada por el Presidente de la Cámara correspondiente, tal y como contempla el art. 54 RCD. Además, se insiste en que la imposibilidad de modificar el orden del día de la sesión plenaria sin acuerdo unánime de la Junta de Portavoces surge de una interpretación muy restrictiva de los artículos 67 y $68 \mathrm{RCD}$, entendiendo, pues, que se está restringiendo el significado del contenido de los preceptos en cuestión. Así las cosas, se estaría trabajando en

35 Vid., STC 238/2012, de 13 de diciembre, FJ 2.

36 Posición que sostienen los recurrentes de inconstitucionalidad contra la Ley Orgánica 2/2004, de 28 de diciembre, de modificación de la Ley Orgánica 6/1985, de 1 de julio, del Poder Judicial (STC 238/2012, de 13 de diciembre, FJ 2.

(C) UNED. Revista de Derecho Político

N. 107 , enero-abril 2020, págs 147-179 
sentido contrario al que se deriva de la aplicación de las reglas interpretativas habituales.

Sin embargo, si los artículos 67.3, 67.4 y 68.1 RCD distinguen de forma expresa varios presupuestos de modificación del orden del día y, sólo en el supuesto recogido por el art. 67.4 RCD se exige acuerdo unánime de la Junta de Portavoces, de ello podría derivarse que en los restantes supuestos no es preciso el acuerdo por unanimidad. Así entendidas las cosas, pierde fuerza la afirmación que sostiene que existe un vicio de forma en la prohibición de modificar el orden del día sin la concurrencia del citado requisito.

Pero además de los requisitos de convocatoria expuestos para que las reuniones celebradas en sede plenaria tengan validez, también hay que prestar atención a la determinación del quórum de la Cámara, esto es, la especificación del número de miembros que en cada Cámara deben estar presentes tanto en el debate como en la posterior votación. El quórum habitual exigido en el Pleno para determinar cuál es la voluntad de la Cámara respecto de la iniciativa legislativa en trámite, en el procedimiento extraordinario de lectura única, es el representado por la mayoría de los integrantes del Congreso y del Senado.

En cuanto a la publicidad de la labor legislativa de los Parlamentos con respecto al acto final del procedimiento legislativo en el que el órgano que representa a la ciudadanía emite su voluntad, debe permitir, en todo caso, que el ciudadano conozca el sentido del voto de sus representantes en Cortes. De otro modo, se dificultaría en extremo el ejercicio del control político por parte de la ciudadanía. En este orden de cosas, la votación en sede plenaria adopta una fórmula pública en la que es posible poner de manifiesto la voluntad particular de cada uno de los miembros, bien expresando en voz alta su postura o a través del mecanismo de mano alzada.

En función del interés existente en dejar testimonio acerca de los datos que vierte este acto procedimental, es conveniente recordar que no solo es posible recoger el resultado de la misma, sino que además, cabe la posibilidad de votar de forma nominal, pudiendo así dar testimonio al sentido del voto emitido por cada uno de los integrantes de las Cámaras. Lo que sí se encuentra expresamente prohibido por el artículo 86 RCD es la votación secreta "en los procedimientos legislativos". Entendemos que el ámbito de aplicación de ese precepto se extiende también a esa decisión inicial del Pleno de optar por el trámite legislativo en lectura única.

Pero a pesar las posibilidades que los Reglamentos Parlamentarios ofrecen para llevar a cabo este acto, la modalidad de votación pública e innominada es la que se adopta en la mayoría de las ocasiones. Y cierto es que la emisión del voto oral es la que podría utilizarse en el procedimiento legislativo de lectura única, pero dada la lentitud de su desarrollo, la opción de emitir el voto a mano alzada es el utilizado habitualmente. Se recurre a la votación nominal únicamente cuando la diferencia cuantitativa está muy poco significada en la Cámara. 


\section{CUÁNDO ADOPTAR LA DECISIÓN DE TRAMITAR EN LECTURA ÚNICA: UNA PROPUESTA ALTERNATIVA.}

Según lo dispuesto por el artículo 150.1 y 2 RCD —y también en paralelo artículo 129.1 RS-, el momento procesal de tomar la decisión de tramitar una iniciativa a través del procedimiento legislativo en lectura única es, respectivamente: en el Congreso, una vez admitido a trámite un proyecto de ley o una vez tomada en consideración una proposición de ley, y antes de abrir plazo de presentación de enmiendas, conforme a los usos parlamentarios vigentes ${ }^{37}$ - a cuya procedencia o improcedencia nos referiremos en un epígrafe posterior-; y en el Senado, después de recibir el texto ya aprobado por el Congreso de los Diputados y antes de abrir plazo para presentar las propuestas de veto a las que se refiere el artículo $129.3 \mathrm{RS}^{38}$.

$\mathrm{Y}$, efectivamente, en esa misma línea ha ido la práctica parlamentaria habida hasta la fecha ${ }^{39}$, si bien que con alguna significada excepción. En algún caso, se procedió a adoptar el acuerdo de tramitar la iniciativa en lectura única con posterioridad al trámite de presentación de enmiendas y una vez verificado que no se había registrado ninguna, lo que, a nuestro juicio, no encontraría impedimento alguno en la regulación parlamentaria ${ }^{40}$ : más allá de que el Reglamento preceptúe que el proyecto de ley debe estar admitido a trámite o que la proposición de ley debe haber superado la toma en consideración, nada impide que la decisión sobre el cauce de tramitación se adopte en cualquier otro momento, estando ya más avanzado el proceso legislativo ordinario, incluso si el texto hubiera pasado ya por Comisión, aunque, evidentemente, en tal supuesto los efectos de la apertura del tramitación en lectura única sólo se proyectarían sobre las condiciones del debate y la votación final en Pleno ${ }^{41}$.

Dicho de otro modo, lo único que se exige reglamentariamente, al menos en el Congreso de los Diputados, es que el texto esté admitido a trámite, y en caso de que

37 Vid., v.g., la Proposición de Ley de modificación de la Ley 42/2015, de 5 de octubre, de reforma de la Ley 1/2000, de 7 de enero, de Enjuiciamiento Civil, para garantizar la efectividad de los actos de comunicación del Ministerio Fiscal (122/000129). BOCG, Congreso de los Diputados, serie B, núm. 162-1, de 6 de octubre de 2017.

38 Así se establece, v.g., en el Proyecto de Ley Orgánica por la que se hace efectiva la abdicación de Su Majestad el Rey Don Juan Carlos I de Borbón.

39 Vid, v.g., la tramitación de la Proposición de Ley Orgánica por la que se modifica la Ley Orgánica 10/1995, de 23 de noviembre, del Código Penal, en materia de delitos de terrorismo (BOCG, Congreso de los Diputados, Serie B: Proposiciones de ley, núm. 211-1, 4 de febrero de 2015).

${ }^{40}$ Lo establecido en el apartado cuarto de la Resolución de la Presidencia del Congreso de los Diputados, de 16 de marzo de 1993, sobre procedimiento a seguir para la tramitación de la reforma de los Estatutos de Autonomía (modificada por Resolución de la Presidencia, de 25 de septiembre de 2018), refuerza la idea de que la decisión de abrir trámite de lectura única se puede hacer en cualquier momento del procedimiento, una vez superada la toma en consideración y antes de que se inicie el debate final de conjunto sobre el texto.

${ }^{41}$ Vid., v.g., la tramitación de la Proposición de Ley Orgánica de modificación de la Ley Orgánica 6/1985, de 1 de julio, del Poder Judicial, relativa a la justicia universal (BOCG, Congreso de los Diputados, serie B, núm. 157-1, de 24 de enero de 2014).

(C) UNED. Revista de Derecho Político

N. 107 , enero-abril 2020, págs 147-179 
procediera, hubiera superado la toma en consideración, pero no se preceptúa que la decisión sobre la tramitación se deba adoptar inmediatamente después, aunque esto sea lo más habitual. Quedaría, pues, la determinación del momento adecuado de adoptar la decisión dentro del margen de autonomía de la que gozan la Mesa, la Junta de Portavoces y el Pleno en el ejercicio de sus funciones, sin que ello signifique en ningún caso la posibilidad de retrotraer el procedimiento ordinario a su fase inicial.

En otras pocas ocasiones, cuando la extraordinaria sencillez del mandato legislativo a aprobar así lo permitía y existía acuerdo unánime de la Cámara, en la misma sesión plenaria en la que se había adoptado la decisión de tramitar el texto en lectura única — una vez sustanciada la toma en consideración_-, se realizó también el debate y la votación de conjunto para aprobar la iniciativa legislativa en cuestión. Éste es también un extremo que expresamente está previsto en alguna norma reglamentaria autonómica $^{42}$.

No obstante, como decimos, la práctica habitual es que la toma en consideración, la adopción del acuerdo de tramitación en lectura única, y su debate y aprobación final se realicen en sesiones plenarias diferenciadas y en ese orden. Y, concretamente, la adopción del acuerdo de tramitación en lectura única suele tener lugar casi en el $100 \%$ de los casos después de la toma en consideración y antes de abrir plazo de presentación de enmiendas - en el Congreso de los Diputados-, y una vez recibido el texto de la Cámara Baja y antes de abrir el plazo de presentación de propuestas de veto — en el Senado-.

Así planteadas las cosas, ¿es éste el momento del procedimiento legislativo más adecuado, especialmente el referido a la decisión del Congreso de los Diputados? Un repaso por la regulación de esta cuestión en los Reglamentos de los Parlamentos de las Comunidades Autónomas puede ofrecernos alguna alternativa minoritaria, pero interesante, a considerar.

Hay dos bloques mayoritarios de Reglamentos Parlamentarios autonómicos que no ofrecen ningún dato relevante:

1. Aquéllos que no se pronuncian en absoluto respecto de cuál deba ser el momento de adoptar la decisión de tramitar una iniciativa en lectura única y que, por tanto, ni siquiera exigen que el proyecto esté admitido a trámite o la proposición de ley tomada en consideración, si bien que de una interpretación sistemática de los mismos debemos inferir que, al menos, debe estar superada la fase de admisión a trámite en ambos casos. Son los supuestos

42 Artículo 165.3 del Reglamento de la Junta General del Principado de Asturias: "Si el Pleno aprobara la tramitación en lectura única por unanimidad, el texto del proyecto de ley será sometido inmediatamente y en la misma sesión a debate y votación final”. 


\author{
de Andalucía ${ }^{43}$, Castilla La Mancha ${ }^{44}$, Cataluña ${ }^{45}$, Extremadura $^{46}$, Galicia ${ }^{47}$,
}

43 Artículo 136 del Reglamento del Parlamento de Andalucía: "Cuando la naturaleza de un proyecto o proposición de ley lo aconsejase o lo permitiese la simplicidad de su formulación, el Pleno de la Cámara, a propuesta de la Mesa y con el acuerdo unánime de la Junta de Portavoces, podrá acordar que dicha iniciativa se tramite directamente y en lectura única ante el Pleno. Este acuerdo comportará la imposibilidad de que pueda presentarse enmienda alguna al proyecto o proposición de ley de que se trate. 2. Adoptado el acuerdo, se procederá a un debate sujeto a las normas establecidas para los de totalidad y, a continuación, el conjunto del proyecto o proposición de ley se someterá a una sola votación".

44 Artículo 168 del Reglamento de las Cortes de Castilla La Mancha: "1. Cuando la naturaleza de un Proyecto o Proposición de Ley o su simplicidad de formulación lo permitan, el Pleno de la Cámara, previo acuerdo de la Junta de Portavoces, a propuesta de la Mesa, podrá acordar que dicho Proyecto o Proposición de Ley se tramite directamente en lectura única ante el Pleno o ante una Comisión. 2. Adoptado el acuerdo se procederá a un debate sujeto a lo dispuesto en el artículo 90 del Reglamento y, a continuación, el conjunto del Proyecto o Proposición de Ley se someterá a una sola votación”.

45 Artículo 138 del Reglamento del Parlamento de Cataluña: "1. Un proyecto de ley puede ser tramitado directamente y en lectura única por el Pleno del Parlamento o por una comisión, si la naturaleza del proyecto lo aconseja o la simplicidad de la formulación lo permite. La tramitación en lectura única debe ser acordada por el Pleno del Parlamento, a propuesta del Gobierno, o a propuesta de la Mesa del Parlamento, oída la Junta de Portavoces, o a iniciativa de ésta. 2. El Grupo Parlamentario promotor de una proposición de ley puede solicitar su tramitación por el procedimiento de lectura única. Corresponde al Pleno del Parlamento acordarla, a propuesta de la Mesa, oída la Junta de Portavoces o a iniciativa de esta, siempre que la proposición de ley cumpla los supuestos habilitantes establecidos en el apartado 1. 3. El debate de la iniciativa legislativa en lectura única se sujeta a las normas establecidas para los debates de totalidad; finalmente, el conjunto de la iniciativa se somete a una sola votación."

46 Artículo 177 del Reglamento de la Asamblea de Extremadura: "El Pleno de la Cámara, a propuesta de la Mesa, de la Junta de Extremadura o de un Grupo Parlamentario, y con el acuerdo de la Junta de Portavoces podrá acordar por mayoría absoluta que cualquier iniciativa legislativa se tramite directamente y en lectura única ante el Pleno en aquellos casos en que lo considere conveniente. Este acuerdo comportará la imposibilidad de que pueda presentarse enmienda alguna al proyecto o propuesta de ley de que se trate. Adoptado el acuerdo, se procederá a un debate sujeto a las normas establecidas para los de totalidad y, a continuación, el conjunto del proyecto o propuesta de ley se someterá a una sola votación".

47 Artículo 134 del Reglamento del Parlamento de Galicia: "Cuando la naturaleza de un Proyecto de Ley lo aconsejara o su simplicidad de formulación lo permita, el Pleno de la Cámara, a propuesta de la Mesa, oída la Junta de Portavoces o a iniciativa de ésta, podrá acordar que dicho Proyecto se tramite directamente y en lectura única ante el Pleno o ante una Comisión. 2. Adoptado el acuerdo, se procederá a un debate sujeto a las normas establecidas para los de totalidad y a continuación el conjunto del Proyecto se someterá a una sola votación".

(C) UNED. Revista de Derecho Político

N. ${ }^{\circ} 107$, enero-abril 2020, págs 147-179 
Navarra $^{48}$, País Vasco $^{49}$ y Valencia ${ }^{50}$.

2. Aquéllos que reproducen la regulación del Reglamento del Congreso de los Diputados y establecen que la decisión habrá de adoptarse tras la admisión a trámite del proyecto de ley, o tras la toma en consideración de la proposición

48 Artículo 158 del Reglamento del Parlamento de Navarra: "1. Cuando la naturaleza de un proyecto o de una proposición de ley foral lo aconseje o su simplicidad de formulación lo permita, la Mesa de la Cámara, de acuerdo con la Junta de Portavoces, podrá acordar que el citado proyecto o proposición se tramite directamente y en lectura única ante el Pleno de la Cámara. 2. Adoptado este acuerdo, la Mesa ordenará la apertura del plazo de enmiendas, que no podrán ser a la totalidad y se presentarán ante la misma, que procederá a su calificación, y que finalizará, salvo que la Mesa fije un plazo distinto, a las doce horas del día anterior a la celebración del Pleno en que haya de debatirse. También se admitirán a trámite las enmiendas "in voce" que presenten los Grupos Parlamentarios que representen, al menos, a la mayoría de los miembros de la Cámara, antes de iniciarse el debate en el Pleno. 3. La sesión plenaria comenzará con la votación sobre la tramitación o no del proyecto o proposición en lectura única. A continuación, en el caso de que el Pleno aprobara dicha tramitación, se procederá al debate del proyecto o proposición de ley foral conforme a las reglas establecidas para los de totalidad, correspondiendo a cada Grupo Parlamentario un solo turno en el que, en su caso, defenderá todas sus enmiendas. En dicho debate intervendrá en primer lugar el proponente de la iniciativa. 4. La no aprobación de la tramitación en lectura única supondrá el rechazo de la correspondiente proposición de ley foral, en su caso, o la tramitación del proyecto de ley foral por el procedimiento ordinario. 5. Finalizado el debate, salvo que algún Grupo Parlamentario solicite votación separada por enmiendas o grupos de enmiendas, la Presidencia someterá a una única votación la totalidad de las enmiendas al articulado formuladas por cada Grupo Parlamentario por el orden de su presentación. 6. Por último se someterá el conjunto del texto, con la incorporación de las enmiendas que hubieran sido aprobadas, a una sola votación. Si el resultado de la votación es favorable, el texto quedará aprobado. En caso contrario, quedará rechazado”.

49 Artículo 163 del Reglamento del Parlamento Vasco: 1. Cuando la naturaleza del proyecto de ley lo aconseje o su simplicidad de formulación lo permita, el Pleno de la Cámara, a propuesta unánime de la Mesa y oída la Junta de Portavoces, podrá acordar que se tramite directamente en lectura única ante el Pleno o ante una comisión. 2. Adoptado tal acuerdo, se procederá a un debate sujeto a las normas establecidas para los de totalidad, sometiéndose seguidamente el conjunto del proyecto a una sola votación. 3. Cuando circunstancias de carácter extraordinario y razones de urgente necesidad lo exijan, el Gobierno podrá hacer uso, sin requerir para ello la previa autorización de la Cámara, del procedimiento de lectura única, ante el Pleno o la comisión correspondiente, para la tramitación de proyectos de ley que no afecten al ordenamiento de las instituciones de la Comunidad Autónoma, al régimen jurídico de las instituciones forales, al régimen electoral, ni a los derechos, deberes o libertades de la ciudadanía".

50 Artículo 139 del Reglamento de las Cortes Valencianas: "1. Cuando la naturaleza de un proyecto o proposición de ley lo aconseje y su simplicidad de formulación lo permita, el Pleno de Les Corts, a propuesta de la Mesa, de acuerdo con la Junta de Síndics, o a iniciativa de ésta, podrá acordar que dicho proyecto o proposición de ley se tramite directamente y en lectura única ante el Pleno o una Comisión. Este acuerdo supondrá el decaimiento del derecho de presentación de enmiendas. 2. Adoptado el acuerdo, se procederá a un debate sujeto a las normas establecidas para los de totalidad, y a continuación, el conjunto del proyecto se someterá a una sola votación. 3. Si no se adoptara el acuerdo, la Mesa remitirá el proyecto o proposición de ley a la Comisión correspondiente, ordenando la apertura del plazo de presentación de enmiendas para que siga su trámite por el procedimiento legislativo común”. 
de ley, a saber, Castilla León ${ }^{51}$, La Rioja ${ }^{52}$ y Asturias $^{53}$. Algunos otros, además, recogen expresamente la posibilidad de presentar enmiendas al texto y prescriben que el plazo para registrar las mismas se abrirá una vez adoptada la decisión de tramitar en lectura única. Así lo establecen Cantabria ${ }^{54}$, Aragón ${ }^{55}$ y Canarias ${ }^{56}$.

3 Fuera de estos dos grupos mayoritarios encontramos tres supuestos de regulación distinta:

51 Artículo 130 del Reglamento de las Cortes de Castilla y León: "1. La Mesa, con el parecer favorable de la Junta de Portavoces, podrá proponer al Pleno de las Cortes la tramitación en lectura única de un proyecto de ley o de una proposición de ley, tomada en consideración, cuando su naturaleza lo aconseje o la simplicidad de su formulación lo permita. 2. Adoptado el acuerdo por el Pleno, se procederá a un debate sujeto a las normas establecidas para los de totalidad y, a continuación, el conjunto del texto se someterá a una sola votación.3. Si el resultado de la votación es favorable, el texto quedará aprobado. En caso contrario, quedará rechazado".

52 Artículo 115 del Reglamento del Parlamento de La Rioja: "Cuando la naturaleza del proyecto o proposición de Ley tomada en consideración lo aconsejen o su simplicidad de formulación lo permita, el Pleno de la Cámara, a propuesta de la Mesa, oída la Junta de Portavoces, podrá acordar que se tramite directamente y en lectura única. 2. Adoptado tal acuerdo se procederá a un debate sujeto a las normas establecidas para los de totalidad, sometiéndose seguidamente el conjunto del texto a una sola votación. Si el resultado de la votación es favorable, el texto quedará aprobado. En caso contrario, quedará rechazado".

53 Artículo 165. bis. 3 del Reglamento de la Junta General del Principado de Asturias: "Sustanciado el trámite a que hace referencia el número anterior, la Mesa de la Cámara, de acuerdo con la Junta de Portavoces, podrá elevar al Pleno propuesta de tramitación en lectura única para el caso de que la proposición de ley fuera tomada en consideración".

54 Artículo 139 del Reglamento del Parlamento de Cantabria: "1. Cuando la naturaleza del proyecto o proposición de ley tomada en consideración lo aconseje o su simplicidad de formulación lo permita, el Pleno, a propuesta unánime de la Mesa, oída la Junta de Portavoces, podrá acordar que se tramite directamente y en lectura única. 2. Adoptado tal acuerdo, no podrán presentarse enmiendas de totalidad, y las enmiendas parciales deberán presentarse a propuesta unánime de todos los Grupos Parlamentarios. 3. El debate estará sujeto a las normas establecidas para los de totalidad, sometiéndose seguidamente el conjunto del texto a una sola votación. Si el resultado de la votación es favorable, el texto quedará aprobado. En caso contrario, quedará rechazado".

55 Artículo 207 del Reglamento de las Cortes de Aragón: "1. Cuando la naturaleza de un proyecto o de una proposición de ley tomada en consideración lo aconseje o su simplicidad de formulación lo permita, la Mesa de la Cámara, de acuerdo con la Junta de Portavoces, podrá acordar que se tramite directamente y en lectura única. 2. Adoptado este acuerdo, se abrirá un plazo máximo de ocho días para la presentación de enmiendas. 3. Las enmiendas, que podrán ser a la totalidad con texto alternativo y al articulado, así como a la totalidad de devolución cuando se trate de un proyecto de ley, se presentarán ante la Mesa de las Cortes, a la que corresponderá su calificación”.

56 Artículo 148 del Reglamento del Parlamento de Canarias:"1. Cuando la naturaleza de un proyecto o proposición de ley tomada en consideración lo aconseje o su simplicidad de formulación lo permita, la Mesa, de acuerdo con la Junta de Portavoces, podrá acordar que se tramite directamente y en lectura única, en cuyo caso ordenará la apertura de un plazo común de presentación de enmiendas a la totalidad y al articulado".

(C) UNED. Revista de Derecho Político

167

N. ${ }^{\circ} 107$, enero-abril 2020, págs 147-179 
a) El Reglamento de la Asamblea de Madrid que es, con diferencia, el más prolijo en la regulación del procedimiento legislativo en lectura única, prescribe en su artículo 168 que "el acuerdo de tramitación en lectura única de una proposición de ley implicará asimismo la toma en consideración de la iniciativa legislativa; adoptado aquél se entenderá tomada en consideración la proposición de ley".

Debemos entender, pues, que primero se debate y se vota si la iniciativa debe tramitarse o no por el procedimiento de lectura única y que, de resultar favorable la votación, se entiende superado también el trámite de toma en consideración. Por el contrario, si la votación fuera desfavorable a la tramitación en lectura única, aunque el Reglamento no lo recoge expresamente, habría de producirse un nuevo debate y votación relativos a la toma en consideración de la iniciativa que ya, lógicamente, seguiría, en su caso, el cauce del procedimiento legislativo ordinario.

Si bien entendemos que, en supuestos concretos, esta solución puede resultar útil desde el punto de vista de la economía procesal y de la agilización de los procedimientos sin que con ello se vulnere ninguna garantía esencial del procedimiento legislativo, no creemos que se trate de una alternativa técnicamente correcta a aplicar de forma general en todos los supuestos. La toma en consideración y la decisión de tramitar una iniciativa por el trámite de lectura única son decisiones y actos parlamentarios completamente distintos en naturaleza y contenido que no se encuentran vinculados en su finalidad, y cuyo debate y votación conviene llevar a cabo separadamente para que la voluntad mayoritaria del Pleno no se vea condicionada por variables que ningún papel han de jugar en la formación y manifestación de dicha voluntad.

b) Tampoco nos parece un referente atendible la regulación recogida en el Reglamento de la Asamblea Regional de Murcia vigente hasta la reforma de 24 de mayo de $2019^{57}$. Su artículo 113.1 todavía iba un paso más allá que el precepto del Reglamento Parlamentario madrileño al establecer que "al decidir los aspectos concretos de la tramitación que deba darse a un asunto, el Consejo de Gobierno, la Mesa de la Asamblea y un Grupo Parlamentario de los constituidos al inicio de la Legislatura, y en relación con el asunto que se tramite a instancias de éste, podrán sugerir, o la Junta de Portavoces directamente acordar, que dicha tramitación se realice por el procedimiento de urgencia. A tal efecto podrá optarse por alguno de los sistemas siguientes: [...] d) Lectura única directamente en el Pleno, sujeta a un solo debate de totalidad sin discusión de enmiendas

57 Los nuevos preceptos que regulan la lectura única en el Reglamento de la Asamblea Regional de Murcia —arts. 142 y 143 - recogen ya los presupuestos habilitantes habituales y se suman al primer grupo de Reglamentos que no se refieren al momento del procedimiento en que debe tomarse esa decisión. 
y concluida con una sola votación sobre el proyecto o documento considerado en su conjunto".

Al margen de la censurable instrumentalización que esta norma reglamentaria hacía del trámite en lectura única como procedimiento de urgencia, la literalidad de este precepto, que ponía en manos de la Junta de Portavoces la decisión de optar o no por este procedimiento abreviado, dejaba la puerta abierta a que ello tuviera lugar antes de la toma en consideración de la iniciativa por el Pleno. No nos parece razonable, dada la lógica concatenación de las decisiones y actos parlamentarios que integran cada uno de los pasos del procedimiento legislativo —en cualquiera de sus variantes-, que la decisión de optar por la vía de la lectura única se adoptara no ya al tiempo de la toma en consideración de la iniciativa sino incluso antes de la misma. La toma en consideración del texto de la iniciativa por parte del Pleno ha de preceder siempre, y en todo caso, a la decisión que la Cámara pueda adoptar respecto al cauce procesal más oportuno para su tramitación.

c) Sí nos parece, por el contrario, muy interesante a estos efectos la regulación que establecía el Reglamento Parlamentario de las Islas Baleares hasta su reforma de 26 de marzo de 2019. El artículo 145.2 preveía que "adoptado tal acuerdo [el acuerdo de tramitar la iniciativa en lectura única] si se hubiesen presentado enmiendas firmadas por las tres quintas partes de los Diputados y las Diputadas de la Cámara, se debatirán y se votarán las mismas. A continuación, o una vez adoptado el acuerdo al que se refiere el apartado anterior, se procederá a un debate sujeto a las normas establecidas para los debates de totalidad, sometiéndose seguidamente el conjunto del texto a una sola votación, con la incorporación, en su caso, de las enmiendas aceptadas".

De ello se deriva que, tras la toma en consideración de la iniciativa pero antes de adoptar el acuerdo de tramitación en lectura única, se abría el plazo de presentación de enmiendas y que éstas se debatían y se incorporaban, en su caso, al texto de la iniciativa también con carácter previo a la adopción del acuerdo sobre la tramitación ${ }^{58}$.

Entendemos que esta solución, que sería aplicable en el Congreso de los Diputados por decisión de la Mesa, en la medida en que su Reglamento no prevé trámite de presentación de enmiendas, pero sí que lo abre conforme a los usos parlamentarios consolidados - y, por tanto, no hay un momento procesal concreto estipulado reglamentariamente para su

${ }^{58}$ El nuevo artículo 153.1 del Reglamento del Parlamento balear ha dado un giro completo a esta cuestión, pues prohíbe expresamente la presentación de enmiendas en cualquier momento de la tramitación.

(C) UNED. Revista de Derecho Politico

N. 107 , enero-abril 2020, págs 147-179 
presentación—, resulta especialmente idónea respecto de la cuestión aquí planteada.

Y ello en virtud de los siguientes motivos: si nos encontráramos ante un supuesto de posible tramitación en lectura única debido a la naturaleza pactada de la norma, no procedería presentación de enmiendas (ni antes, ni después de adoptado el acuerdo de tramitación); pero en el caso de que la lectura única pudiera proceder por motivo de la simplicidad de la formulación del texto, sería muy conveniente que las enmiendas se presentaran con anterioridad a la adopción del acuerdo de tramitación.

Así, la Mesa, la Junta de Portavoces y el Pleno antes de optar por un tipo de tramitación legislativa u otro, dispondrían del texto de la iniciativa en su integridad, esto es, el contenido de la iniciativa y las enmiendas presentadas a la misma. De este modo sería posible calibrar mejor la simplicidad o la complejidad de aquello que habría de sustanciarse en lectura única ante el Pleno sin pasar por la Comisión Legislativa correspondiente. O, dicho a contrario, podrá evitarse así la hipótesis improbable pero no imposible de que aquella iniciativa que, por presentar formulación simple se hubiera optado por su tramitación en lectura única, y al ser objeto posteriormente de numerosas y complejas enmiendas, hicieran necesario el estudio en Comisión omitido al haber optado por el procedimiento legislativo que estudiamos.

\section{EL CÓMO ADOPTAR LA DECISIÓN DE TRAMITAR EN LECTURA ÚNICA.}

\subsection{El valor del precedente parlamentario.}

El hecho de que en un determinado momento y por las concretas circunstancias que pudieran concurrir en un supuesto señalado, las Cámaras hubieran optado por tramitar una iniciativa legislativa a través del procedimiento en lectura única en el Congreso de los Diputados y/o en el Senado, no puede ni debe vincular al Parlamento en relación con la toma de decisiones posteriores relativas al tipo de tramitación al que someten otras iniciativas legislativas.

Cada proyecto o proposición de ley constituye una iniciativa independiente de las anteriores y posteriores, y cada una de ellas puede seguir un iter legislativo diferente como consecuencia de la concurrencia o no de todas aquellas variables que los Reglamentos Parlamentarios recogen como supuestos habilitadores de la vía procedente en cada caso. Las circunstancias que configuran el contenido, la forma y el contexto de cada iniciativa legislativa son diferentes, por lo que ningún sentido tendría buscar precedentes idénticos que pudieran vincular a las Cámaras a la hora de optar por una determinada vía procedimental, ni cuando se trate de la misma ley y sus sucesivas 
reformas, ni cuando se trate de leyes distintas que pudieran compartir naturaleza o condiciones estructurales y formales.

No existe prescripción normativa ni general — respecto del conjunto de los procedimientos legislativos_- ni particular — respecto del procedimiento abreviado en lectura única- que imponga a los órganos de las Cámaras la sujeción al precedente parlamentario. Tampoco existe testimonio documental ni verbal derivado de las entrevistas con los Letrados de las Cámaras que dé cuenta de que en alguna ocasión la Mesa, la Junta de Portavoces o el Pleno, hayan justificado su decisión de tramitar una iniciativa en lectura única aludiendo a la similitud o identidad de dicha iniciativa con un precedente anterior.

$\mathrm{Y}$, efectivamente, en este entendimiento la jurisprudencia constitucional ${ }^{59}$ ha manifestado que no existe obligación de tramitar por el mismo cauce procesal aquellas iniciativas legislativas que guarden similares características al afirmar que: "No existe tampoco prescripción normativa alguna que imponga al Congreso de los Diputados la sujeción a sus precedentes en relación con las decisiones sobre los procedimientos de tramitación de las iniciativas legislativas [...]. De nuevo aquí entra en juego la libertad de opción de la Cámara sobre el procedimiento a seguir dentro del abanico de posibilidades que le brinda su Reglamento" ${ }^{60}$. Con el único matiz relevante de que "la quiebra inmotivada del propio precedente" puede resultar inconstitucional solo en el caso de que "afecte a las condiciones de ejercicio del cargo representativo" 61. Evidentemente, si la Mesa y el Pleno se apartaran del precedente y no tramitaran una determinada iniciativa en lectura única, optando por el procedimiento legislativo ordinario, no se estarían vulnerando las previsiones del art. 23. 2 CE sino, muy al contrario, reforzando sus garantías.

Sirva como ejemplo de lo que venimos afirmando la diferente tramitación que las Cámaras han dado a una norma tan relevante como la Ley Orgánica del Tribunal Constitucional, tanto en su aprobación inicial como en sus sucesivas reformas. Y es que la Ley Orgánica 2/1979, de 3 de octubre, del Tribunal Constitucional ${ }^{62}$ fue remitida a la Comisión Constitucional del Congreso de los Diputados por acuerdo de la Mesa, de 15 de mayo de 1979, y se tramitó por el procedimiento de urgencia ${ }^{63}$. Por su parte, la Ley Orgánica 12/2015, de 22 de septiembre, de modificación de la Ley Orgánica del Tribunal

59 Vid., DE LA PEÑA RODRÍGUEZ, L. (2009). "Los órganos parlamentarios en la jurisprudencia constitucional”, Jurisprudencia parlamentaria. Eusko Legebiltzarra. Seminario celebrado en Vitoria-Gasteiz los días 29 y 30 de enero de 2009, 143 y ss.

${ }^{60}$ STC 215/2016, de 15 de diciembre, FJ 5c) con el único matiz relevante de que "la quiebra inmotivada del propio precedente" puede resultar inconstitucional solo en el caso de que "afecte a las condiciones de ejercicio del cargo representativo".

61 STC 110/2019, de 2 octubre, FJ 3 B a).

${ }^{62}$ Vid., v.g., Proyecto de ley aprobado en Consejo de Ministros de 20 de abril de 1979 y presentado en el Congreso de los Diputados el 9 de mayo de 1979 (BOE, núm. 239, de 5 de octubre de 1979).

63 Vid., v.g., Proyecto de Ley Orgánica 121/000060 por la que se modifica la Ley Orgánica 2/1979, de 3 de octubre, del Tribunal Constitucional (BOCG, Congreso de los Diputados, Serie A, núm. 44-1, de 24 de mayo de 1979).

(C) UNED. Revista de Derecho Politico

N. ${ }^{\circ}$ 107, enero-abril 2020, págs 147-179 
Constitucional para el establecimiento del recurso previo de inconstitucionalidad para los Proyectos de Ley Orgánica de Estatuto de Autonomía o de sus modificaciones, se tramitó por el procedimiento ordinario ${ }^{64}$. Esta última reforma es el precedente inmediato de otra modificación a esta Ley que se aprobaría apenas tres semanas después: la Ley Orgánica 15/2015, de 16 de octubre, de reforma de la Ley Orgánica del Tribunal Constitucional para la ejecución de las resoluciones del Tribunal Constitucional como garantía del Estado de Derecho ${ }^{65}$. Esta reforma fue sometida, sin embargo, a una tramitación en lectura única y urgencia en el Congreso de los Diputados, mientras que el Senado optó por tramitar esta iniciativa por el cauce procedimental ordinario ${ }^{66}$.

\subsection{La dicotomía mayoría simple vs. mayorías reforzadas.}

La decisión de vehicular la tramitación de una determinada iniciativa legislativa a través del procedimiento abreviado en lectura única ha de adoptarse por mayoría simple y no por ninguna fórmula de mayoría cualificada, ni mucho menos por unanimidad de la Cámara, tal y como se deduce claramente de lo dispuesto en el artículo 79.2 CE y de la interpretación que del mismo ha venido realizando nuestro Tribunal Constitucional.

Así, el artículo 79.2 CE establece que los acuerdos que adopten las Cámaras serán válidos siempre que sean "aprobados por la mayoría de los miembros presentes, sin perjuicio de las mayorías especiales que establezcan la Constitución o las leyes orgánicas y las que para elección de personas establezcan los Reglamentos de las Cámaras”. Esto es, la regla general que preceptúa la Constitución para todo tipo de acuerdos parlamentarios, también los acuerdos de tipo de tramitación legislativa, será la mayoría simple salvo que expresamente la propia Constitución o el bloque de la constitucionalidad prevea una mayoría cualificada.

Exigencia de mayorías cualificadas encontramos, por ejemplo, para la aprobación de los Reglamentos de las Cámaras (mayoría absoluta, ex artículo 72 CE), para la declaración de una sesión plenaria como secreta (mayoría absoluta, ex artículo $80 \mathrm{CE}$ ), para la aprobación o reforma de leyes orgánicas (mayoría absoluta, ex artículo $81 \mathrm{CE}$ ), para la investidura el Presidente del Gobierno en primera vuelta (mayoría absoluta,

${ }^{64}$ Vid., Proposición de Ley Orgánica de modificación de la Ley Orgánica 2/1979, de 3 de octubre, del Tribunal Constitucional 122/000207, para el establecimiento del recurso previo de inconstitucionalidad para los Proyectos de Ley Orgánica de Estatuto de Autonomía o de su modificación (BOCG, Congreso de los Diputados, serie B, núm. 233-1, de 14 de julio de 2015).

${ }^{65}$ Vid., Proposición de Ley Orgánica de reforma de la Ley Orgánica 2/1979, de 3 de octubre, del Tribunal Constitucional, para la ejecución de las resoluciones del Tribunal Constitucional como garantía del Estado de Derecho. 122/000213 (BOCG, Congreso de los Diputados, serie B, núm. 237-1, de 4 de septiembre de 2015).

${ }^{66}$ Vid., Proposición de Ley Orgánica de reforma de la Ley Orgánica 2/1979, de 3 de octubre, del Tribunal Constitucional, para la ejecución de las resoluciones del Tribunal Constitucional como garantía del Estado de Derecho (BOCG, Senado, apartado I, núm. 613-4209, de 15/10/2015). 
ex artículo 99.3 CE), para la aprobación de una moción de censura (mayoría absoluta, ex artículo 113.1 CE), para la autorización de la declaración del estado de sitio (mayoría absoluta, ex artículo 116.4 CE), para la aprobación por el Senado de medidas excepcionales en una Comunidad Autónoma (mayoría absoluta, ex artículo 155.1 CE), para la aprobación de reformas de la Constitución (mayoría de 3/5 ó 2/3, según el caso, ex artículos 167 y $168 \mathrm{CE}$ ), o para el nombramiento de miembros del Consejo General del Poder Judicial o del Tribunal Constitucional (mayoría de 3/5, ex artículos 122.3 y 159.1 CE, respectivamente). No existe, pues, precepto constitucional ni reglamentario que establezca una mayoría distinta a la mayoría simple para adoptar el acuerdo de tramitación de una iniciativa legislativa en lectura única ${ }^{67}$.

A confirmar esta tesis ha venido nuestro Tribunal Constitucional, que ha tenido ocasión de pronunciarse en numerosas ocasiones sobre el particular. Así, la jurisprudencia constitucional ha dictaminado que, con carácter general, "la formación de la voluntad de las Cámaras a través de cualquier procedimiento legislativo debe ordenarse con arreglo a un principio mayoritario que es el engranaje básico del principio democrático y la base de nuestro modelo parlamentario, siendo la mayoría cualificada o la unanimidad un requisito excepcional que limita, pero no suprime, dicho principio mayoritario. Sobre esta base es plausible afirmar que los requisitos de unanimidad ni son inconstitucionales per se ni son una obligación reglamentaria, sino que se configuran como una opción excepcional que puede escoger el legislador"68.

$\mathrm{Y}$, concretamente, respecto del acuerdo de tramitación de una iniciativa legislativa en lectura única, ha estipulado recientemente que "la falta de consenso entre los Grupos Parlamentarios en orden a la tramitación de la proposición de ley por el procedimiento en lectura única tampoco afecta a la constitucionalidad de dicha tramitación [...]. El consenso político que pudiera suscitar el proyecto o la proposición de ley es algo totalmente ajeno a la concurrencia de los requisitos de simplicidad de formulación o naturaleza del texto normativo que permitan o aconsejen su tramitación por el procedimiento en lectura única [...]. En otras palabras, la decisión de recurrir a este procedimiento parlamentario ha de adoptarse por mayoría simple y no por unanimidad o mayoría cualificada alguna, tal y como se deduce de lo dispuesto en el artículo 79 CE, y de la interpretación realizada por este Tribunal del juego de mayorías descrito por la norma fundamental, al reconocer que la norma generalmente seguida en los procedimientos parlamentarios es el recurso a la mayoría simple, siendo

${ }^{67}$ Incluso podríamos plantearnos, dada la literalidad del artículo 79.2 CE, que habilita a los Reglamentos Parlamentarios para determinar una mayoría cualificada distinta de la mayoría simple solo para los acuerdos consistentes en "elección de personas", sin aludir a ningún otro tipo de acuerdo parlamentario, si los Reglamentos del Congreso de los Diputados y del Senado hubieran podido establecer mayorías cualificadas para el acuerdo de tramitación de iniciativas en lectura única, o si no lo hicieron precisamente por carecer de habilitación constitucional ex artículo 79.2 CE.

${ }^{68}$ Vid., al respecto, SSTC 212/1996, de 19 de diciembre, FJ 11; 160/1987, de 27 de octubre, FJ 2; 127/1994, de 5 de mayo, FJ 3 A); 5/1981, de 13 de febrero, FJ 21 A); y 124/2003, de 19 de junio, FJ 11.

(C) UNED. Revista de Derecho Politico

N. ${ }^{\circ} 107$, enero-abril 2020, págs 147-179 
la excepción la previsión de mayorías cualificadas en aras de obtener un mayor consenso para proteger más eficazmente los derechos e intereses de las minorías, o con otro objetivo razonable $[\ldots]$. ${ }^{69}$.

Admite el Tribunal Constitucional, por tanto, que el mayor o menor consenso parlamentario no afecta a la concurrencia de los presupuestos habilitantes de la lectura única, que deberá apreciarse por mayoría simple del Pleno. Sin embargo, en una sentencia posterior (STC 139/2017, de 11 de septiembre, FFJJ 1 y 7) el Tribunal procede a vincular por primera vez algunas de las más relevantes consecuencias procesales de tramitar una iniciativa en lectura única, a la existencia o no de acuerdo unánime del Pleno para su tramitación.

Si hubiera tal unanimidad, entiende el Tribunal que, de no abrirse trámite de enmiendas, ninguna vulneración se produciría del ius in officium del parlamentario; por el contrario, si el acuerdo no se adopta por unanimidad, y no se abre posteriormente trámite de enmiendas, sí que se incurre en lesión de ese ius in officium de los integrantes de ambas Cámaras ${ }^{70}$. A nuestro juicio, la pertinencia o no de apertura de trámite de enmiendas debe ir vinculada no al grado de consenso en la adopción del acuerdo de acudir al procedimiento abreviado en lectura única, sino a las concretas condiciones del presupuesto habilitante que concurra en cada caso.

Finalmente, debemos señalar que, lógicamente, distinto tratamiento debe darse a la determinación de la mayoría que se deba entender exigida para aprobar finalmente un texto legislativo que ha sido tramitado por el procedimiento de lectura única. La tramitación en lectura única del proyecto o proposición de ley en nada afecta a la mayoría requerida para su aprobación final, que dependerá de la condición procesal de la iniciativa ratione materiae. Es decir, de si la variante abreviada en lectura única se proyecta sobre el procedimiento legislativo ordinario que se aprueba por mayoría simple, o sobre un procedimiento legislativo especial que requiera para su aprobación definitiva una mayoría cualificada.

\section{CONCLUSIONES.}

Pese a que en la práctica parlamentaria el Pleno de la Cámara suele decidir libérrimamente la tramitación en lectura única de las iniciativas legislativas, tal decisión es una facultad excepcional y condicionada sometida a los límites que establece el artículo 150 RCD.

Excepcional porque exceptúa la regla general de que sea exclusivamente la Mesa el órgano que decida sobre la tramitación de cualquier iniciativa parlamentaria. Y

${ }^{69}$ Vid., SSTC 185/2016, de 3 de noviembre, FJ 5 c); 129/2013, de 4 de junio, FJ 9; 179/1989, de 2 de noviembre, FJ 7; y 238/2012, de 13 de diciembre, FJ 4.

70 STC 139/2017 FFJJ 1 y 7. 
como tal excepción a la regla general, su ámbito y alcance deben interpretarse de modo restrictivo.

Y condicionada en un doble sentido: porque el RCD establece la necesaria concurrencia de dos presupuestos habilitantes (que su naturaleza lo aconseje o la simplicidad de su formulación lo permita) y porque corresponde a la Mesa la verificación de tales presupuestos y, en consecuencia, proponer o no al Pleno la tramitación en lectura única.

Así, como ha admitido el Tribunal Constitucional en la muy reciente STC 110/2019, de 2 de octubre, y a diferencia de lo defendido por la doctrina mayoritaria, en el caso de que la Mesa de la Cámara entendiera que no concurre ninguno de los presupuestos habilitantes del art. 150 RCD, podría no proponer al Pleno la tramitación en lectura única de la iniciativa pese a que, vía Junta de Portavoces, a la Mesa le constara el acuerdo mayoritario o incluso unánime del Pleno al respecto.

Una vez realizada la propuesta de la Mesa, entonces sí correspondería ya al Pleno decidir, por motivos de oportunidad política, tramitar o no la iniciativa en lectura única, esto es, pese a que la Mesa verificara que, en efecto, se cumple alguno de los presupuestos habilitantes, el Pleno podría optar por no ir al procedimiento abreviado y tramitar la iniciativa conforme a las reglas del procedimiento legislativo ordinario.

Tales presupuestos habilitantes son que la naturaleza de la iniciativa lo aconseje o la simplicidad de su formulación lo permita. En relación con el primero de ellos, las únicas leyes que poseen una naturaleza distinta a las demás que aconseja su tramitación en lectura única, esto es, la omisión de la fase de Comisión, son aquéllas que tienen la condición de norma prepactada que solo precisa un voto de ratificación de las Cortes Generales (v.g., LORAFNA). Sin embargo, el hecho de que otro tipo de normas pudieran llegar al Parlamento con un contenido ya muy consensuado fuera de la sede parlamentaria no cambia su naturaleza ni las convierte en norma pactada al amparo de ninguna disposición constitucional o legislativa por lo que en tales supuestos no concurriría este primer presupuesto habilitante.

Por su parte, el segundo de ellos que la simplicidad de su formulación lo permita no debe identificarse necesariamente con brevedad del texto o con que su contenido resulte comprensible e inteligible. La clave estaría en poner en conexión las condiciones del texto con las consecuencias procedimentales que la lectura única comporta: el parámetro para medir caso por caso hasta qué punto un texto es suficientemente sencillo como para omitir su paso por Comisión es cómo de prescindible pueda ser esa fase del procedimiento sin que se vulnere con ello el contenido esencial del ius in officium de los parlamentarios.

Para este segundo supuesto, además, proponemos que el trámite de presentación de enmiendas se realice — ningún impedimento reglamentario hay para ello— antes de la adopción de la decisión sobre la apertura del procedimiento en lectura única pudiendo de este modo los órganos de la Cámara valorar mejor la concurrencia de este segundo presupuesto habilitante dado que una iniciativa originalmente muy sencilla podría en hipótesis ser objeto de numerosas y complejas enmiendas cuya admisión podría convertir en inexcusable su paso por Comisión Legislativa.

(C) UNED. Revista de Derecho Politico 


\section{BIBLIOGRAFÍA.}

Alzaga Villaamil, O. (1976). "Contribución al estudio del derecho parlamentario”, Revista de derecho público, 62.

Araujo Díaz de Terán, M. (2012). “Comentario al artículo 150”, en Ripollés Serrano, M.R. (Coord.). Comentarios al Reglamento del Congreso de los Diputados, Madrid, Congreso de los Diputados.

ArCe JanÁriz, A. (1994). "El derecho de enmienda visto por el Tribunal Constitucional”, Revista Española de Derecho Constitucional, 41.

Biglino Campos, P. (2011). Voz "Procedimiento Legislativo", en Aragón Reyes, M. (Dtor.), Temas Básicos de Derecho Constitucional, Tomo II, Organización General y Territorial del Estado, Navarra, Civitas.

Cassagne, J. C. (1998). Derecho Administrativo, Buenos Aires, Abeledo Perrot.

De La Peña Rodríguez, L. (1998). Calificación y admisión a trámite de iniciativas legislativas, Madrid, V jornadas de Derecho Parlamentario.

- (2009). "Los órganos parlamentarios en la jurisprudencia constitucional", Jurisprudencia parlamentaria. Eusko Legebiltzarra. Seminario celebrado en Vitoria-Gasteiz los días 29 y 30 de enero de 2009.

Dickmann, R. (1995). "L'esercizio dell'iniziativa legislativa", Rivista trimestrale di Diritto pubblico, 1.

GALEOTTI, S. (1975). Contributo alla Teoria del procedimento legislativo, Urbino, Facoltà di Giurisprudenza, Universidad degli Studi di Urbino, Giuffrè.

García de Entrerría, E. y Fernández Rodríguez, T. R. (1985). Curso de Derecho Administrativo, Madrid, Civitas.

García Martínez, M. A. (1987). El procedimiento legislativo, Madrid, Congreso de los Diputados.

García Roca, J. (2014). Pautas para una reforma constitucional, Madrid, Aranzadi.

GARcía-Escudero MÁrQuez, P. (2005). "El procedimiento legislativo ordinario en las Cortes Generales: regulación, fases y tipos”, Teoría y Realidad Constitucional, 16.

- (2006). El procedimiento legislativo ordinario en las Cortes Generales, Madrid, CEPC.

- (2007). El procedimiento agravado de reforma de la Constitución de 1978, Madrid, CEPC.

- (2009). "La reforma del artículo 135: ¿son suficientes trece días para la tramitación parlamentaria de una reforma constitucional", Cuadernos de Derecho Público, 38.

- (2011), Manual de técnica legislativa, Civitas, Madrid.

García-Escudero Márquez, P. y Pendás García, B. (1999). "Comentario al artículo 72.2 de la Constitución. Autogobierno de las Cámaras. Sesiones Conjuntas”, en Alzaga Villaamil, O. (Dtor.). Comentarios a la Constitución Española de 1978, Madrid, Edersa.

García-Trevijano Fos, J. A. (1964). “Tratado de Derecho Administrativo”, Revista de Derecho Privado, Madrid. 
Garrido Falla, F. (2012). Tratado de Derecho Administrativo, Madrid, Tecnos.

- (2008). Los procedimientos legislativos especiales en las Cortes Generales, Madrid, Congreso de los Diputados.

- (2019). "La tramitación de la reforma constitucional mediante procedimientos legislativos abreviados: un problema de límites procedimentales", Teoría y Realidad Constitucional, 43.

Martínez Sospedra, M. (2010). "La costumbre como fuente de Derecho Parlamentario. Precedentes, usos y prácticas parlamentarias en la doctrina del Tribunal Constitucional”, Corts. Anuario de Derecho Parlamentario, 23.

Merino Merchán J. F. y De La Peña Rodríguez, L. (1991). "Las facultades de calificación de las enmiendas por las Mesas de las Cámaras”, Revista de las Cortes Generales, 23.

Redondo García, A. M. (2001). "El derecho de enmienda como instrumento de integración del pluralismo político en la fase central de los procedimientos legislativos de las Cortes Generales", Revista de Derecho Político, 50.

Ridao Martín, J. (2018). "La tramitación directa de las leyes: el procedimiento de lectura única a revisión”, Revista General de Derecho Constitucional, 28.

Santaolalla López, F. (1981). "La ley y la autorización de las Cortes a los Tratados Internacionales", Revista de Derecho Político, 11.

- (2006). "Decreto ley, ley y tratado internacional. Comentario a la STC 155/2005, de 9 de junio", Teoría y Realidad Constitucional, 18.

- (2013). Derecho Parlamentario Español, Madrid, Dyckinson.

Torres Muro, I. (1987). Los órganos de gobierno de las Cámaras. Presidente, Mesa y Junta de Portavoces en el sistema parlamentario español, Madrid, Congreso de los Diputados, 1987.

- (1998). "Los derechos de los parlamentarios", Revista de Derecho Político, 44.

Title:

A review of the excepcional competence of the Full House ex article 150 of the Rules of Congress of Deputies.

\section{Summary:}

1. COMPETENT BODIES TO DECIDE THE PROCESS OF SINGLE READING. 1.1 The competences of the Table and the limits of the enabling circumstances. 1.2 The procedural conditions of the decision of the Full House. 2. THE PROCEDURAL MOMENT OF THE DECISION

(C) UNED. Revista de Derecho Político 
TO OPT FOR A SINGLE READING: AN ALTERNATIVE PROPOSAL. 3. HOW TO MAKE THE DECISION TO PROCEED WITH SINGLE READING. 3.1 The value of parliamentary precedent. 3.2 The dichotomy simple majority vs reinforced majority. 4. CONCLUSIONS. 5. Bibliography.

\section{Resumen}

El artículo 150 del Reglamento del Congreso de los Diputados establece que, cuando la naturaleza de un proyecto o proposición de ley tomada en consideración lo aconseje o la simplicidad de su formulación lo permita, el Pleno de la Cámara, a propuesta de la Mesa, oída la Junta de Portavoces, podrá acordar que se tramite directamente y en lectura única. En este trabajo se analiza, de una parte, si la decisión de optar por este cauce procesal abreviado es un juicio meramente político que debe adoptar el órgano plenario y, si al hacerlo de ese modo, se está dando cumplimiento o no al cometido que el Reglamento Parlamentario encomienda a la Mesa de la Cámara. Concretamente, examinamos si para que el Pleno pueda finalmente decidir que la tramitación de una concreta iniciativa sea a través de esta vía procesal extraordinaria es inexcusable la propuesta previa de la Mesa de la Cámara y si este órgano de gobierno puede y debe revisar la concurrencia de los presupuestos habilitantes previstos por el Reglamento Parlamentario antes de hacer la propuesta. Proponemos al respecto una reinterpretación del alcance de esta facultad de la Mesa separándonos del criterio doctrinal mayoritario. Asimismo, acometemos un análisis detallado de la fase del procedimiento en la que se debe decidir la tramitación de una iniciativa por el procedimiento en lectura única para, seguidamente, plantear aquellas soluciones alternativas que, en nuestro criterio, resultan más oportunas y compatibles con la actual redacción del Reglamento Parlamentario. Finalmente se analiza si la decisión que adopta cada una de las Cámaras acerca de la tramitación de una iniciativa legislativa por esta vía procesal abreviada en un determinado momento y ante la concurrencia de unas concretas circunstancias vincula o no a la otra Cámara con respecto a esa misma iniciativa. Estudiaremos, asimismo, el valor que adquiere el precedente parlamentario en relación a otras iniciativas de similar condición y pondremos de manifiesto la relevancia que alcanza la dicotomía existente entre mayorías simples y reforzadas con respecto a la toma de decisiones relativas a la adopción de este cauce procesal extraordinario.

\section{Abstract}

The article 150 of the Rules of Congress of Deputies establishes that, if proposed by the Table of the House, and once heard by the all Party Assembly, the Full House can agree to process an initiative directly and in a single reading. We will also analyse, on one hand, whether the option to choose this abbreviated legal channel is simply a political judgement which the Full House should adopt, and thus comply or not with the 
task which the Parliamentary Rules has entrusted to the Table of the House. On the other hand we will study whether the Full House can finally decide to process a particular initiative through this legal channel or if the previous proposal to the Table of the House is necessary, and whether this governmental body should comply — with the production of a strictly techno/juridical judgement - to the proposals established by juridical order for the processing of a legislative initiative using the procedure of a single reading. For this reason we will study whether the proposal for process by single reading by the Table is obligatory or not, even in the case in which after being seen by the all Party Assembly it is verified that the Plenary will vote in majority in favour of implementing this abbreviated legislative procedure. Also, we will undertake a detailed analysis of the procedural moment in which the process of an initiative with a single reading should be decided, and thus present alternative solutions which, to our judgement, are more appropriate and compatible with the current Parliamentary Rules. Finally, we will undertake an exhaustive examination of the value acquired by the parliamentary precedent in this type of abbreviated legislative procedure and show the level of relevance reached by the existing dichotomy between simple and absolute parliamentary majorities with respect to decision making relative to the adoption of this legal channel.

\section{Palabras clave:}

Procedimiento legislativo adecuado, órgano competente para decidir, presupuestos habilitantes, Mesa de la Cámara, Pleno.

\section{Key words:}

Adequate legislative procedure, competent body to make decisions, enabling circumstances, Table of the House, Full House. 